\title{
Do Games Reduce Math Anxiety? A meta-analysis.
}

\author{
Pierpaolo Dondio $^{a, *}$, Viacheslav Gusev $^{a}$ and Mariana Rocha ${ }^{a}$ \\ ${ }^{a}$ School of Computer Science, Technological University Dublin, Dublin, Ireland
}

\section{ARTICLE INFO}

\section{Keywords:}

math anxiety

Game-based Learning

Meta-analysis

\begin{abstract}
A B S TR ACT
In this paper we present the first meta-analysis of the effectiveness of game-based interventions to reduce students' level of math anxiety. After performing a search for randomised studies relevant to game-based intervention for math anxiety, 16 effect sizes with a total of 686 participants described in 11 peer-review articles met the selection criteria. A random-effects meta-analysis indicated a small and non-significant reduction of math anxiety (mean effect size $E S=-0.32, C I=[-0.64,0.01])$. The results were moderated by several factors: non-digital games were more effective, while digital games had a negligible mean effect size of $E S=-0.13$, $C I=[-0.33,0.08]$. The effect size was moderated also by the total duration of the intervention, to the advantage of longer interventions, and by the type of gameplay: games had a greater effect on math anxiety reduction when they promoted collaborative and social interactions. Such features were only present in non-digital games, while all the digital games analysed were singleplayer. In the final section of the paper, we discuss future possible research directions. The weak results obtained indicated the need to develop and test games explicitly designed for math anxious students. This will require the investigation of the relationship between game features and math anxiety through the analysis of the behaviour of anxious and non-anxious students at play. Among the features that an anxiety-aware game could employ, we suggest collaborative gameplay, social interactions, adaptability, features promoting intrinsic motivation and embedding real-time measurements of math anxiety.
\end{abstract}

\section{Introduction}

Math anxiety (MA) is defined as "a debilitating negative emotional reaction towards mathematics" (Hill, Mammarella, Devine, Caviola, Passolunghi and Szúcs (2016)). It is an enduring type of anxiety that represents a trait of an individual (Luttenberger, Wimmer and Paechter (2018)). Affecting 1 in 6 students, this condition is more common among primary school girls than boys (Luttenberger et al. (2018); Hunsley and Flessati (1988); Rubinsten, Bialik and Solar (2012); Beilock, Gunderson, Ramirez and Levine (2010); Stoet, Bailey, Moore and Geary (2016); Van Mier, Schleepen and Van den Berg (2019)), thereby worsening the existing problem of gender inequality in STEM education (Stoet et al. (2016)). MA can be already identified in primary school children (Ramirez, Gunderson, Levine and Beilock (2013)), potentially hindering their future professional performance and career choices (McMullan, Jones and Lea (2012)). A recent study on MA and female students' vocational interests suggests that girls with high levels of MA are less interested in careers with high math proficiency, regardless of their numerical performance (Levy, Fares and Rubinsten (2021)). On the other hand, male students did not have their career choice affected by MA levels.

Treatments of MA may involve both mathematics interventions aimed to work on the cognitive ability of the individual and treatments for anxiety such as systematic desensitization and cognitive behaviour 36 therapy (Dowker, Sarkar and Looi (2016)).

In the last decade, game-based learning has been suggested as a possible treatment for MA based on positive evidence collected in closely related research fields. Indeed, the efficacy of digital game-based learning (DGBL) for mathematics education has been widely demonstrated (Hung, Huang and Hwang (2014); Byun and Joung (2018)). Digital games can support problem-solving and critical thinking and help students to comprehend abstract mathematics concepts (Homer, Raffaele and Henderson (2020)). DGBL has been shown to promote engagement and increase pupils' self-confidence (Ku, Kwak, Yurov and Yurova (2014a); Gil-Doménech, Berbegal-Mirabent and Borsot (2017)), develop positive attitudes towards maths (Afari, Aldridge, Fraser and Khine (2013); Ke (2006)), and positively increase the cognitive abilities of children suffering from maths learning disabilities (Benavides-Varela, Callegher, Fagiolini,

\footnotetext{
*Corresponding author Rocha)

@pierpaolo.dondio@tudublin.ie (P. Dondio); d20125420@mytudublin.ie (V. Gusev); mariana.rocha@tudublin.ie (M.

ORCID(s): 0000-0001-7874-8762 (P. Dondio); 0000-0003-3451-0327 (M. Rocha)
} 
Leo, Altoè and Lucangeli (2020)). This positive evidence has fuelled the idea that games could be the no-brainer solution to engage math anxious students, change their attitude towards the subject and help treating their anxiety. But what is the evidence to support this assumption to-date? Despite the positive results in other fields, a preliminary review of game-based interventions to reduce math anxiety reported contrasting results (Dondio, Gusev, Santos and Rocha (2021)).

In order to shed light on the issue, we propose the first meta-analysis of the efficacy of game-based interventions (digital and non-digital) to reduce math anxiety in children and young adults. Previous meta-analyses targeting math anxiety exist, but their focus was usually on the relationship between math anxiety and math performance (Namkung, Peng and Lin (2019); Barroso, Ganley, McGraw, Geer, Hart and Daucourt (2021); Ma (1999)) or on the efficacy of treatments such as cognitive behavioural therapy (Bicer, Perihan and Lee (2020)). Game-based interventions were also the target of several meta-analyses investigating the effect of games on cognitive learning (Girard, Ecalle and Magnan (2013)), active aging (Vazquez, Otero, García-Casal, Blanco, Torres and Arrojo (2018)) and healthy behaviour promotion (Zhou, Occa, Kim and Morgan (2020)). The closest meta-analysis to ours is the one performed by Fadda, Pellegrini, Vivanet and Zandonella Callegher (2022) on the effect of game-based interventions on student motivation in mathematics. However, math anxiety was considered outside the scope of their meta-analysis and therefore to date no meta-analysis has been performed on the effect of game-based interventions on math anxiety.

We have selected peer-reviewed randomised trials that included a pre- and post- measure of MA and an intervention consisting of one or multiple sessions where participants played games or participated in game-like activities. A set of moderators were considered to better understand the significant factors that could increase the efficacy of game-based interventions.

The results of our analysis could provide insights not only on the efficacy of game-based interventions but help teachers to understand what type of games could be used to support anxious students in formal or informal education.

\subsection{Objectives}

The objective of this meta-analysis is to synthesize quantitatively the findings concerning the effects of gamebased interventions on the level of maths anxiety of participants, measured before and after the intervention. The central research question is the following:

- Q1. Do game-based interventions significantly reduce the level of math anxiety of the participants?

For the purpose of this review, the reduction is defined as the difference between a post- and a pre- measure of MA quantified by a self-repoorted validated scale. This is in line with previous meta-analysis involving measures of math anxiety. While MA can be measured in multiple ways, including behavioral and neurophysiological measures, traditional self-descriptive questionnaire has been shown to be reliable tools (Cipora, Artemenko and Nuerk (2019)).

We also conducted further analyses to explore how the specific characteristics of the intervention influence the effects of digital games on math anxiety. We considered the digital or non-digital nature of the games, the type of games used, the length of the intervention, the type of reward system used by the game, the type of gameplay. We therefore explored the following research questions:

- Q2. Does the effect vary by

a) the digital or non-digital nature of the game used?

b) the age group and school level?

c) the total length and the number of sessions of the intervention?

d) the reward systems present in the game?

e) the type of gameplay ( single-player, multi-player, collaborative ...)?

Regarding the characteristics of the participants, we considered their age and the school level:

- Q3. Does the effect vary by the age group and school level?

\section{Methods}

The meta-analysis follows the Preferred Reporting Items for Systematic-review and Meta-Analysis-Protocols (PRISMAP, Moher, Shamseer, Clarke, Ghersi, Liberati, Petticrew, Shekelle and Stewart (2015)). 


\subsection{Eligibility criteria}

The following eligibility criteria were set for the studies to be included:

- Study design: studies had to use randomized designs; we included also studies without a control group (i.e. experimental studies including a pre- and post- measurement of math anxiety and an intervention on one or more experimental groups).

- Participants: studies had to be conducted on students in regular schools, including primary, secondary and university-level undergraduate courses. Participants were not pre-filtered.

- Intervention: studies had to include a game-based intervention were participants took part to one or more game session in a school context; moreover, a control group must include participants doing business-as-usual or no intervention.

- Measures of maths anxiety: studies had to include, as a dependent variable, a self-report (self-descriptive ) validated measure of maths anxiety returning a numerical score.

- Data: studies had to report sample size, arithmetic means and standard deviations (SD) of treatment and control groups before and after the intervention. Alternatively, study can report directly the sample size and the effect size of each experimental and control groups.

- Timing: studies had to have been carried out after the year 2000.

- Language: the studies' reports had to be available in English or provide a partial translation in English were the methods and results are clearly described.

- Publication status: we included published works, such as articles in peer-reviewed journals, peer-reviewed conference, book chapters and dissertations.

\subsection{Information sources}

A first literature search was carried out from May to August 2021 and it was refreshed in January 2022. The search included the following online bibliographical databases for published literature (ERIC; SCOPUS) and a specific database for grey literature(ProQuest Dissertations and Theses Global) and the GOOGLE Scholar database.

\subsection{Research Strategy}

A combination of keywords and Boolean operators were used. We used a set of keywords related to game-based learning ("video game" OR "computer game" OR "seriousgame" OR "educational game" OR "digital game*" OR "game-based learning" OR "DGBL"), a second set of keywords were related to math anxiety ("maths anxiety" OR "math anxiety" OR "mathematics anxiety" ) and a set of keywords was used to identify randomized trials with pre-post test design: ((pre-test AND post-test) OR "effect size" OR "control group"). The literature search was limited to the English language and to publication time, according to the eligibility criteria. The details of the query executed on each electronic database is described in section 1.1 of the supplemental materials.

\subsection{Study selection and data collection process}

The articles selected for the current meta-analysis were the result of a process of screening selection. Articles were screened for eligibility by three independent authors (VG, MR and PD) and disagreements were resolved through discussions until consensus was reached. The full-text was used to screen each study. To identify game-based interventions we referred to the definition of game proposed by Juul (2010), who describes a game as "a rule-based formal system with a variable and quantifiable outcome, where different outcomes are assigned different values, the player exerts effort in order to influence the outcome, the player feels attached to the outcome, and the consequences of the activity are optional and negotiable" (p. 8, Juul (2010)). The data extraction format used to classify each study is presented in section 1.2 of the supplemental materials. 


\subsection{Data items}

The following information were collected from each study:

- publication data (authors, years, type of article),

- grade of the participants

- intervention characteristics, including control group activity, number of intervention weeks, number of sessions, minutes for each session, game platform, name of the digital game.

- measure of math anxiety (type of instrument used and the description of the instrument in term of number of items and response scale)

- data to compute effect sizes, including sample sizes, means and standard deviations for pre-test and post-test for each experimental groups and control group (if present).

- the value of potential effect size moderators. Details about factors that could influence the effect size of the interventions were collected from each selected paper. Candidate moderators included games' features (type of game, gameplay mode, reward system, sophistication of mechanics), participants' characteristics (age group), and study features (number of game sessions, total gameplay duration). The final list of moderators and their description is provided in section 2.7.2

\subsection{Study risk of bias assessment}

To ensure the studies quality, several methods were used. Our strategy was to perform a sensitivity analysis for every choice that potentially increased bias and/or variance. Every possible risk of bias identified by a reviewer, concerning the theoretical and methodological characteristics of a study, was discussed among all the authors. The main risks of bias and the methods to mitigate them are now listed.

1. The inclusion in the meta-analysis of studies without a control group represented a source of bias. Effect sizes without a control group could be positively biased, and our choice to use as effect size the $d_{p p c 2}$ metrics (Morris (2008)) required to impute control group data for the studies without one. Missing control group data were estimated using relevant similar studies, as described in details in the next section 2.7. The extra variance introduced by the imputation was mitigated by strict selection criteria to include relevant similar studied and by performing a sensitivity analysis on the imputed values.

2. Leave-one-out sensitivity analysis was carried out to ensure that no single study had a substantial influence on the overall results.

3. Different sources of dependency among effect sizes within a study were taken into account by meta-analysis approaches; the estimates of effect sizes sharing a common control group (multiple-treatment studies) were considered as a source of dependency and treated following Cohrane guidelines. In order for multiple experiments from the same study to be included in the meta-analysis, each experimental group had to (1) describe a gamebased intervention, (2) use a distinct set of participants and (3) use a sufficiently different game. Condition (3) was introduced to decide whether to merge or keep distinct the various experimental groups. If condition (3) was not satisfied, the experimental groups were merged together. Additionally, a sensitivity analysis was conducted to account for multiple scenarios where multiple-treatment studies were kept separated or merged

4. An additional sensitivity analysis on the value of the correlation between pre- and post- test was performed.

\subsection{Data Synthesis and Analysis}

We analysed studies' results considering effect size and variance based on the $d_{p p c 2}$ index suggested by Morris (2008). $d_{p p c 2}$ allows to quantify the treatment effect size as the difference between the mean pre-post change in the treatment group and the mean pre-post change in the control group, divided by the pooled pre-test standard deviation:

$$
d_{p p c 2}=c_{p} \frac{\left(M_{p o s t, T}-M_{p r e, T}\right)-\left(M_{p o s t, C}-M_{p r e, C}\right)}{S D_{\text {pooled }, p r e}}
$$


where $M_{p r e, T}, M_{\text {post }, T}, M_{\text {pre }, C}, M_{\text {post }, C}$ are, respectively, the pre- and post- mean scores of the treatment group, and the pre- and post- mean scores of the control group. $S D_{\text {pooled,pre }}$ is the pooled pre-test standard deviation, computed considering only the pre-test standard deviation of the two groups, and $c_{p}$ is a bias adjustment for small sample size. Compared to other indexes, $d_{p p c 2}$ offers better results in terms of bias, precision, and robustness to heterogeneity of variance (Morris (2008)). The $d_{p p c 2}$ values were interpreted according to the criteria suggested by Cohen (2013): small effects from 0.2 to 0.5 ; medium effects from 0.5 to 0.8 ; large effects greater than 0.8 . The $d_{p p c 2}$ was calculated using raw mean scores, standard deviation, and sample size of the treatment and control groups reported in the studies. In order to compute the $d_{p p c 2}$ variance, the correlation between pre- and post-test scores was needed. However, only Rocha and Dondio (2021) reported this correlation, with a value of $r_{\text {pre-post }}$ equal to 0.72 . Thus, $r_{\text {pre-post }} 0.72$ was used as a reference value for all the studies.

For the studies that did not have a control group, control group data were estimated. Our strategy was to use control group data from similar relevant studies describing interventions to reduce MA, and to perform a large sensitivity analysis to account for the variance introduced by the imputation process. In order to compute $d_{p p c 2}$ for the studies with no control group, equation (1) required to estimate $M_{p r e, C}, M_{p o s t, C}$ and $S D_{p r e, C}$ (used in the computation of $S D_{\text {pooled,pre }}$. We refer to the imputed values as $M_{\text {pre }, C}^{I}, M_{\text {post }, C}^{I}$ and $S D_{\text {pre,C }}^{I}$

The pre-intervention values $M_{\text {pre, } C}^{I}$ and $S D_{\text {pre, } C}^{I}$ were pooled from studies reporting measures of math anxiety collected either before an intervention or in studies with no intervention, such as MA surveys or studies used to validate a scale. More specifically, for each study with a missing control group, the inclusion criteria for relevant studies were: (1) a peer-review study reporting MA measures, (2) math anxiety levels were assessed using the same scale as the study with the missing control group, (3) math anxiety levels were assessed before the intervention or (4) assessed in a study with no intervention and (5) the study was not included in this meta-analysis.

After the pre-values $M_{p o s t, C}^{I}$ and $S D_{p r e, C}^{I}$ were estimated, the imputation of the post- mean value $M_{\text {post }, C}^{I}$ was obtained by first estimating the expected change in math anxiety in a control group after carrying out the intervention on the experimental group. We collected a second set of relevant studies describing an intervention to reduce math anxiety and including a control group in their design. The inclusion criteria for this second set of similar studies were as follows: RCT studies where (1) math anxiety was the dependent variable, (2) the participants were students, (3) the study was not part of this meta-analysis, (4) the scale used to measure math anxiety was one of the scales used in the 4 studies with the missing control group and (5) the type of control used was traditional learning or no intervention.

For each of the selected studies we computed the pre-post mean change $\delta_{C}$ represented by the following formula:

$$
\delta_{C}=\frac{\mu_{\text {post }, C}-\mu_{\text {pre }, C}}{\sigma_{\text {pre }, C}}
$$

where $\mu_{\text {post }, C}, \mu_{\text {pre,C }}$ and $\sigma_{\text {pre,C }}$ were the pre- and post- means and the pre- standard deviation of MA values for each study. The overall mean value for $\delta_{C}$ was computed with a random-effects model. Finally, a value for $M_{\text {post }, C}^{I}$ was obtained with the formula $M_{p o s t, C}^{I}=M_{p r e, C}^{I}+\delta_{C} S D_{p r e, C}^{I}$. After the meta-analysis was performed, a large sensitivity analysis on the imputed data were conducted to verify if (and at what values) the overall results changed significantly.

All the analysis was conducted with the statistical software R (Team et al. (2018)), the random-effects model meta-analysis was computed with the restricted maximum likelihood method of the R package Metafor (Viechtbauer (2010)).

\subsubsection{Sensitivity Analysis and evaluation of publication bias}

We ran 3 sensitivity analyses to investigate robustness of the results. Firstly, we used the leave-one-out method to evaluate how results would change if studies were excluded one at the time from the analysis. If there is a significant change in the effect size value when a single study is deleted, then the results are interpreted as lack of homogeneity and unreliable (Viechtbauer (2010)). Secondly, we evaluated our results when different values are used for $r_{\text {pre-post }}$, the correlation between the pre- and post-tests. Thirdly, we performed a sensitivity analysis on the imputed control group values to check to what extent the overall results depended on them.

The publication bias was assessed using the funnel plot with the trim and fill method (Duval and Tweedie (2000), Rothstein, Sutton and Borenstein (2006)). 


\subsubsection{Effects of moderators}

According to Talan, Doğan and Batdı (2020), conducting moderator analysis can specify the relevant effect size in a more detailed way. The present meta-analysis examined if the overall effect size of game-based interventions was moderated by some the characteristics of the studies included in the analysis. When considering the features of the studies and the games employed, some common features arose such as the gameplay, the complexity of game mechanics, the number of playing sessions, the total duration of each intervention. The complete list of moderators adopted in this study was as follow:

- Type of game: This category classifies the games as digital or non-digital. Digital games motivate students to learn mathematics and enhance their confidence and engagement (Ku, Chen, Wu, Lao and Chan (2014b); Gil-Doménech and Berbegal-Mirabent (2019)), leading to positive perceptions of the subject. However, in a meta-analysis comparing the impact of digital and non-digital games, Talan et al. (2020) suggested that nondigital games have a higher effect size as it provides more opportunities for peer interaction and flexibility of design. This contradiction among studies highlights the importance of considering as a possible moderator the media used to deliver the game.

- Total gameplay duration: This category presents, in minutes, how much time the participants spent playing. When the paper described a range of duration (e.g., 5 to 7 weeks, between 10 and 15 minutes per week), the shortest one was considered. This category can be a relevant moderator as demonstrated by previous metaanalysis. One example is a study published by Sitzmann (2011), where learners with unlimited access to an educational game demonstrated better learning outcomes when compared to those with limited access.

- Number of sessions: This category classifies games as Single session or Multiple sessions considering how many times the game was played during the intervention. The selection of this potential moderator aroused after identifying the variety of protocols adopted in the studies selected. According to a meta-analysis conducted by Clark, Tanner-Smith and Killingsworth (2016), educational game conditions involving multiple game-play sessions result in better learning outcomes when compared to non-game conditions.

- Gameplay mode: This category classifies the games according to the way players interact. Games can be classified according to modes. Single-player (where the player can only play by him/herself, without interacting with others); Multi-player competitive, where players compete against each other; Multi-player collaborative, where players collaborate with each other; Collaborative team competition, where teams of players collaborate with each other, but compete with other teams. The efficacy of each gameplay mode is still controversial according to the literature. While some researchers show that single-player and multi-player collaborative conditions have better effect sizes (Vogel, Vogel, Cannon-Bowers, Bowers, Muse and Wright (2006)), others suggest that team-playing is a more efficient approach (Wouters, Van Nimwegen, Van Oostendorp and Van Der Spek (2013)).

- Reward system: According to previous literature, the reward system of a game can affect attention and motivation in the learning process. For example, behaviour analysts suggest one must carefully consider not only what to use as a reward, but also how and when learners should gain access to those rewards (Linehan, Kirman, Lawson and Chan (2011)). The present meta-analysis classifies the games according to the reward system. Games where players receive only scores after every well-performed task are classified as Scores. Games where players receive other elements and/or have their rewards adapted to the complexity of the task are classified as More than score.

- Sophistication of mechanics: We considered that the complexity of game mechanics can be a relevant moderator in our meta-analysis. Even though studies have proven the efficacy of games in learning, many educational games do not use all the possibilities these tools can offer to promote higher-order thinking and deep learning (Lowrie and Jorgensen (2015)), usually just replicating activities already performed using pen and paper. To assess the complexity of the game mechanics, we classified the games as School-like activities or Additional mechanics.

- Age group: This category considers the fact games can be used for different audiences and teach different school levels. For each study, age was encoded as the average age of the participants. When only the class grade was provided, we mapped it into the corresponding children age for the country of the study. If the age was provided as an interval (such as "students aged 10-11-year-old"), the mid-point of the interval was used. 


\section{Results}

\subsection{Search Results}

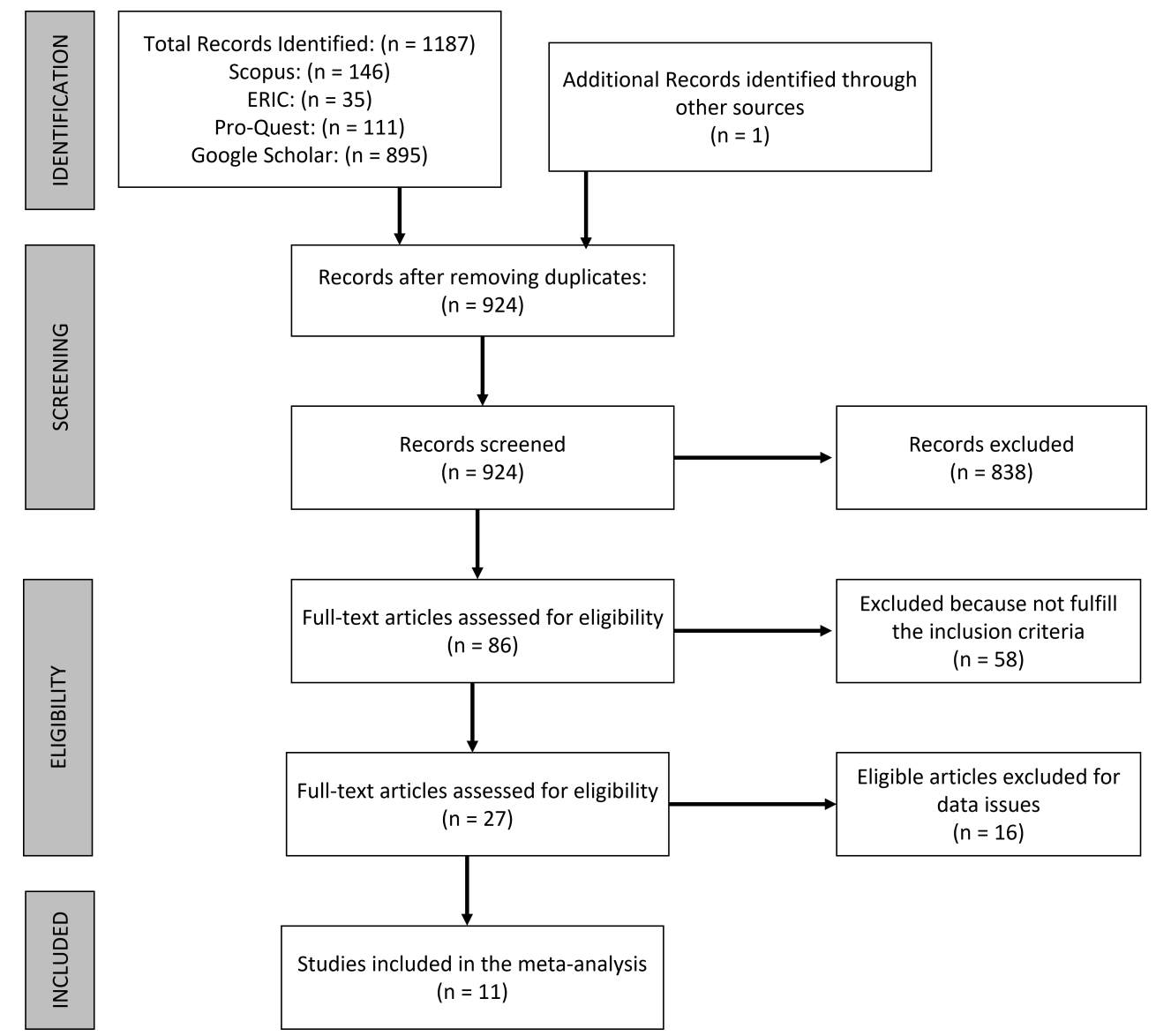

Figure 1: Flow diagram of systematic search and study selection

Figure 1 shows the number of articles retrieved and screened. A total of 1187 articles were identified from the four databases used. After removing the duplicated entries, 838 articles were discarded since not relevant to the topic of this meta-analysis, leaving 86 articles relevant to math anxiety and game-based learning. Of these 86 articles, 59 articles were excluded because they were not experimental studies. Of the remaining 27 articles describing an experimental intervention, 16 articles did not report the necessary data for computing effect sizes and they were therefore discarded. Common reasons were the absence of pre- or post-test measurement, absence of quantitative data or different scales used between pre- and post- analysis. As a result, 11 articles were kept for this study containing 16 distinct effect sizes.

\subsection{Risk of bias within studies and imputation of missing data}

During the screening process, the article by Van Eck (2006) was discarded since the value of math anxiety in the post-test and the value in the pre-test did not seem to be measured on the same scale. In the study by Huang, Huang and $\mathrm{Wu}$ (2014), the scores used to quantify math anxiety were reversed (a higher score corresponded to less math anxiety) and therefore the sign of the effect size was change. Two further sources of bias identified were the use of multiple-treatments groups and the absence of a control group in some studies. The results are descibed in the following sections.

\subsubsection{Multiple-treatment studies}

Five papers presented more than one experimental group. Each experimental group was kept as a separate intervention, since each represented a game-based intervention on a distinct set of participants, and we considered the games 
Table 1

Descriptive statistics of the studies included in the review

\begin{tabular}{|r|l|c|c|c|c|c|}
\hline & Author & Year & $\mathrm{N}_{T}$ & $\mathrm{M} / \mathrm{F}$ & $\mathrm{N}_{C}$ & $\mathrm{M} / \mathrm{F}$ \\
\hline 1 & C-M. Hung & 2014 & 23 & $11 / 12$ & 23 & $13 / 10$ \\
\hline 2 & S-M WANG & 2020 & 73 & $38 / 35$ & 70 & $34 / 36$ \\
\hline 3 & H.M.Z. Alanazi & 2020 & 28 & $28 / 0$ & 32 & $32 / 0$ \\
\hline 4 & & & 48 & $24 / 24$ & & \\
5 & B. Jensen et al. & 2013 & 52 & $28 / 24$ & 56 & $28 / 28$ \\
6 & & 51 & $30 / 21$ & & \\
\hline 7 & A.J. Walker & 2018 & 25 & $19 / 31$ & $\mathrm{NA}$ & $\mathrm{NA}$ \\
8 & & 25 & & $\mathrm{NA}$ & $\mathrm{NA}$ \\
\hline 9 & Y.M. Huang & 2014 & 29 & $16 / 13$ & $\mathrm{NA}$ & $\mathrm{NA}$ \\
\hline 10 & Y.M. Huang & 2014 & 27 & $15 / 12$ & $\mathrm{NA}$ & $\mathrm{NA}$ \\
\hline 11 & E. Novak & 2015 & 16 & $1 / 15$ & $\mathrm{NA}$ & $\mathrm{NA}$ \\
\hline 12 & E. Novak & 2015 & 14 & $1 / 13$ & $\mathrm{NA}$ & $\mathrm{NA}$ \\
\hline 13 & S. Vanbecelaere & 2020 & 107 & $-/-$ & 101 & $-/-$ \\
\hline 14 & E.N. Castellar & 2014 & 25 & $18 / 7$ & 26 & $18 / 8$ \\
\hline 15 & M. Rocha & 2020 & $\mathbf{7 7}$ & $37 / 40$ & $\mathrm{NA}$ & $\mathrm{NA}$ \\
\hline 16 & F. Santos & 2021 & 43 & $12 / 31$ & 23 & $8 / 15$ \\
\hline \hline & TOTAL & & $\mathbf{6 8 6}$ & $\mathbf{2 7 8 / 2 7 8 *}$ & $\mathbf{3 3 1}$ & $\mathbf{1 3 3 / 9 7 ^ { * * }}$ \\
\hline & & &
\end{tabular}

used different enough to keep the experimental groups distinct. The only exception is the study by Santos (2021). After contacting the author, based on her suggestions we decided to merge the two experimental groups into one, since the game interventions were considered too close. In section 3.2 of the supplemental material, we describe each of the experimental groups analysed and discuss our choices. We also report an additional sensitivity analysis (Table S4 in supplemental material) showing how merging some or all the experimental groups together did not impact the overall results of this meta-analysis.

\subsubsection{Control group data imputation}

Before performing our meta-analysis, we estimated the control group data for the 4 studies without a control group, following the procedure described in section 2.3. A more detailed description of the imputation procedure, the list of additional studies used and the imputed values are reported in the supplemental material section 3 and Tables S1, S2 and S4. Using the control group data of 15 relevant studies, the mean effect size of the pre-post mean change in the level of MA in the control groups was estimated at $\delta_{C}=-0.076\left(d f=14, Q=62.3, p=0.00, I^{2}=86.0 \%\right)$ with a confidence interval of $[-0.24,0.09]$. As expected, the estimated change in MA levels in control group was a very small and non-significant decrease.

\subsection{Study characteristics}

11 studies describing 16 experiments met the inclusion criteria. All articles were published from 2013 to 2021; in 4 out of 11 studies, there was no control group. In 10 out of 11 studies, the age of students was in the range of 7-12 years, while in the study by Novak and Tassell (2015) participants were university students (aged 18-21). Nine studies were done in primary school, one in high school and one at university. 12 out of 16 studies were conducted using digital games and 4 using non-digital board games. Tables 1 and 2 provide information on the studies included in the meta-analysis.

\subsection{Random-effects model meta-analysis}

After the imputation, we performed the meta-analysis on the values of $d_{p p c 2}$ to test the effect of digital-game interventions on MA reduction. The random effects meta-analysis showed a mean effect size of $d_{p p c 2}=-0.32$ with a $95 \%$ confidence interval of $[-0.64,0.01]$, meaning that, in general, the value of math anxiety decreased with a small effect size. The upper bound of the confidence interval is greater than zero, suggesting that the negative effect size was not statistically significant. The forest plot in figure 2 shows that 12 out of 16 interventions were not significantly different from the zero line of no reduction. The conclusion is therefore that game-based interventions have a small 
Table 2

Description of the experiments included in the meta-analysis

\begin{tabular}{|c|c|c|c|}
\hline Author & Intervention & math anxiety Scale & Control group(s) \\
\hline $\begin{array}{l}\text { C-M. Hung } \\
(2014)\end{array}$ & $\begin{array}{l}\text { A set of different learning games } \\
\text { aligned to the curriculum and deliv- } \\
\text { ered on e-books }\end{array}$ & $\begin{array}{l}\text { Fennema-Sherman Mathemat- } \\
\text { ics Attitude scale (Fennema } \\
\text { and Sherman (1976)) }\end{array}$ & $\begin{array}{l}\text { Traditional teaching } \\
\text { without e-books }\end{array}$ \\
\hline $\begin{array}{l}\text { S-M } \quad \text { WANG } \\
(2020)\end{array}$ & Various card games for math learning & $\begin{array}{l}\text { mAMAS (Carey, Hill, Devine } \\
\text { and Szúcs (2017)) }\end{array}$ & Traditional learning \\
\hline $\begin{array}{l}\text { H.M.Z. Alanazi } \\
(2020)\end{array}$ & $\begin{array}{l}\text { ARMG Game: recreational non- } \\
\text { digital game-based activities per- } \\
\text { formed during the educational pro- } \\
\text { cess }\end{array}$ & $\begin{array}{l}\text { Math Anxiety Scale for Chil- } \\
\text { dren (Chiu and Henry (1990)) }\end{array}$ & Traditional Learning \\
\hline $\begin{array}{l}\text { B. Jensen } \\
(2013)\end{array}$ & $\begin{array}{l}3 \text { interventions: the digital game } \\
\text { Math Garden by Klinkenberg, } \\
\text { Straatemeier and van der Maas } \\
\text { (2011) at } 3 \text { different levels }\end{array}$ & $\begin{array}{l}\text { Math Anxiety Scale for Chil- } \\
\text { dren (Chiu and Henry (1990)) }\end{array}$ & Traditional Learning \\
\hline $\begin{array}{ll}\text { A.J. } & \text { Walker } \\
(2018) & \end{array}$ & $\begin{array}{l}\text { Two interventions: (1) A set of non- } \\
\text { digital Math games and (2) the non- } \\
\text { digital card game MeeMo (Skelton } \\
\text { and Atkinson (2014)) }\end{array}$ & $\begin{array}{l}\text { SEMA (Wu, Amin, Barth, } \\
\text { Malcarne and Menon (2012)) }\end{array}$ & No control group \\
\hline Huang (2014) & $\begin{array}{l}\text { Two interventions: (1) a } \\
\text { DGBL system based on the In- } \\
\text { put-Process-Outcome Game Model } \\
\text { by Garris, Ahlers and Driskell (2002) } \\
\text { and (2) the same DGBL system } \\
\text { with a diagnostic mechanism and } \\
\text { indicative feedback }\end{array}$ & $\begin{array}{l}\text { Mathematics Anxiety Rating } \\
\text { Scale (MARS) (Alexander and } \\
\text { Martray (1989)) }\end{array}$ & No control group \\
\hline Novak (2015) & $\begin{array}{l}\text { Two interventions: (1) playing AVG } \\
\text { (action video games) and (2) playing } \\
\text { non-AVG games }\end{array}$ & $\begin{array}{l}\text { Fennema-Sherman Mathemat- } \\
\text { ics Attitude scale (Fennema } \\
\text { and Sherman (1976)) }\end{array}$ & No control group \\
\hline $\begin{array}{l}\text { Vanbecelaere } \\
(2020)\end{array}$ & $\begin{array}{l}\text { The Number Sense Game (Lin- } \\
\text { sen, Maertens, Husson, Van den } \\
\text { Audenaeren, Wauters, Reynvoet, } \\
\text { De Smedt, Verschaffel and Elen } \\
(2015))\end{array}$ & $\begin{array}{l}\text { CMAQ-R (Ramirez, Chang, } \\
\text { Maloney, Levine and Beilock } \\
(2016))\end{array}$ & Traditional learning \\
\hline $\begin{array}{l}\text { Castellar } \\
(2014)\end{array}$ & $\begin{array}{l}\text { The digital game Monkey Tales } \\
\text { (Vandercruysse, Maertens and Elen } \\
(2015) \text { ) }\end{array}$ & SEMA (Wu et al. (2012)) & Traditional learning \\
\hline Rocha (2020) & $\begin{array}{l}\text { The digital game Once Upon a Maths } \\
\text { in Rocha and Dondio (2021) }\end{array}$ & mAMAS (Carey et al. (2017)) & No Control Group \\
\hline Santos (2021) & $\begin{array}{l}\text { The digital game Calcularis (Käser, } \\
\text { Baschera, Kohn, Kucian, Richtmann, } \\
\text { Grond, Gross and von Aster (2013)) }\end{array}$ & $\begin{array}{l}\text { MathAS by Carmo and } \\
\text { Figueiredo (2005) }\end{array}$ & Traditional learning \\
\hline
\end{tabular}

and non-significant effect on the reduction of math anxiety after an intervention. The results are subject to a level of heterogeneity significantly high $\left(I^{2}=91.4 \%\right)$.

We also tested the overall effect of the 12 interventions based on digital games included in the meta-analysis. The overall effect of the studies analysed was 0.13 with an associated $95 \%$ confidence interval of [0.33, 0.08], clearly showing how digital games intervention had a negligible effect on math anxiety reduction. The forest plot for the digital games interventions is shown in figure 3. Note how the heterogeneity was much lower than the one computing considering all the studies $\left(I^{2}=68.8 \%\right)$, partially due to the removal of the outlier study by Alanazi (2020).

\subsection{Evaluating the sensitivity of the analysis}

Three sensitivity analyses were performed: the sensitivity to the exclusion of one study at the time, the sensitivity to the value of $r_{\text {pre-post }}$ (pre-post test correlation) and the sensitivity to the control group data imputation for the four 


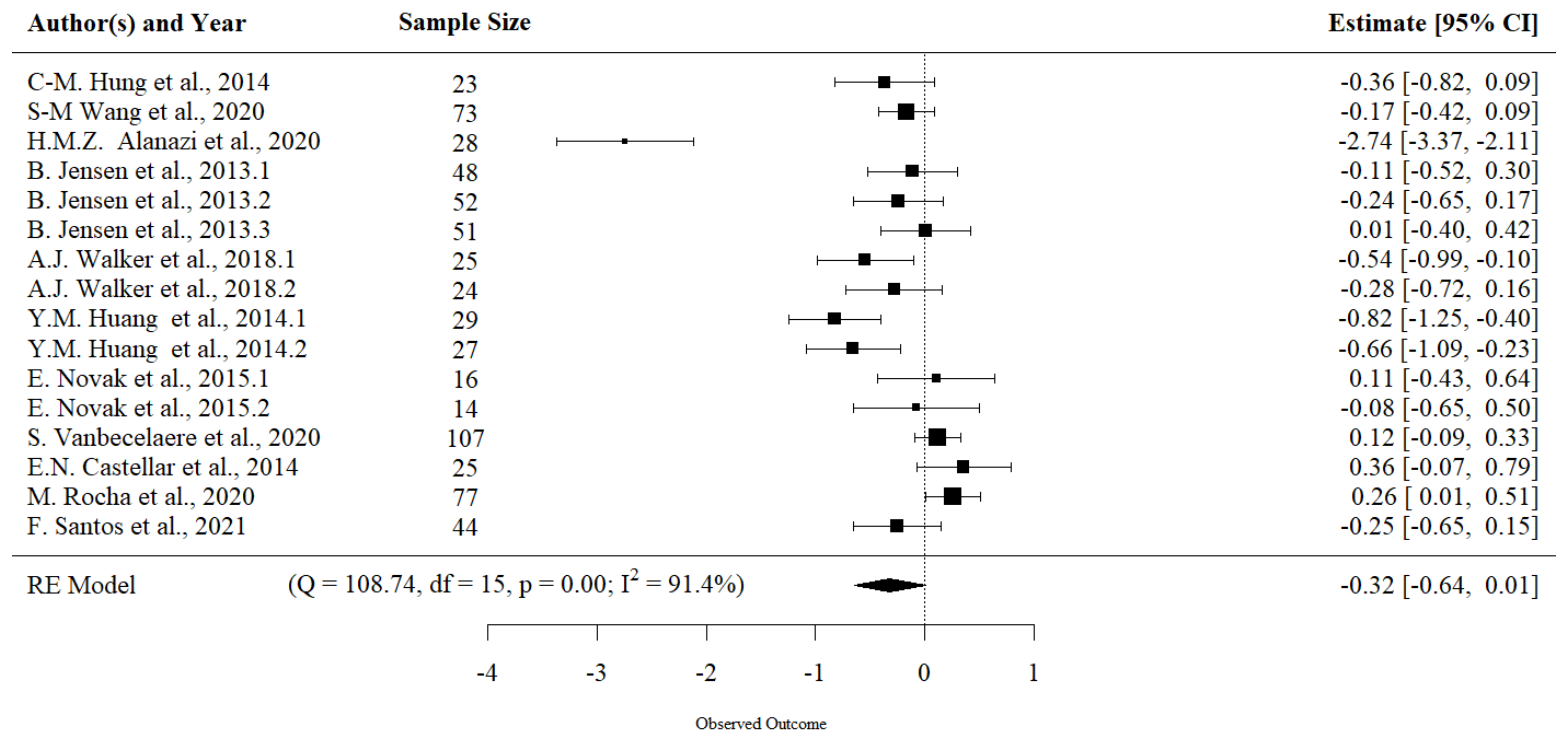

Figure 2: Forest plot. Each square represents the effect size of the study together with $95 \%$ confidence interval. The size of the symbol is proportional to the study's weight. The overall effect of the studies analysed was -0.32 with an associated confidence interval of $[-0.64,0.01]$

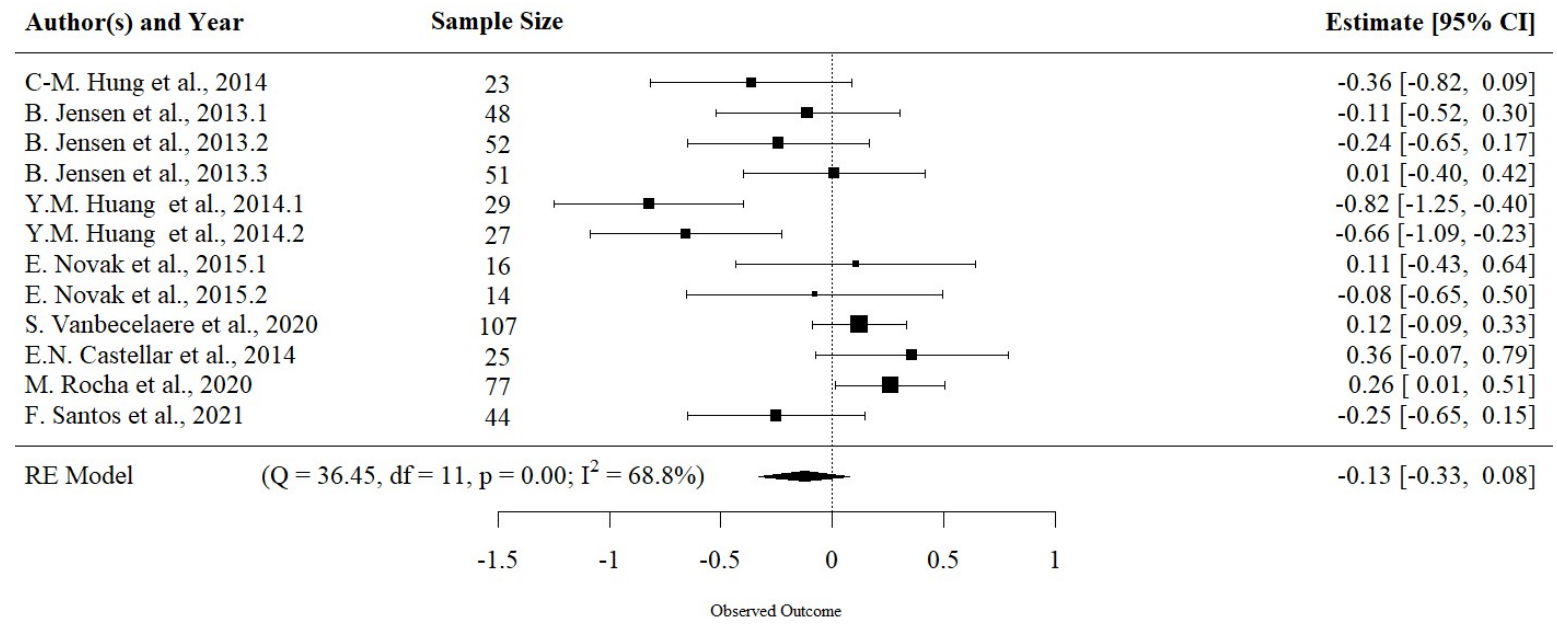

Figure 3: Forest plot for the studies including a digital-game intervention. Each square represents the effect size of the study together with $95 \%$ confidence interval. The size of the symbol is proportional to the study's weight. The overall effect of the studies analysed was -0.13 with an associated confidence interval of $[-0.33,0.08]$. Note how the heterogeneity was much lower than the one including all the studies (forest plot in figure 2).

studies without it. Overall, the sensitivity analysis confirmed the robustness of the results. The results of the leaveone-out method for all the studies are shown in Table 3 and the results for digital interventions in Table 4 . The $d_{p p c 2}$ for all the studies varied between -0.36 and -0.16 , the effect size remained consistently between small-medium values. Regarding confidence intervals, they remained large and only 4 out of 16 times they did not include zero, as evidence of a borderline statistical significance of the results. Regarding digital games (Table 4), the results were even more stable, since none of the values of $d_{p p c 2}$ resulting from the leave-one-out method were significant and they varied from -0.17 to -0.06 . 


\begin{tabular}{rrrr}
\hline Paper & effect size & ci.lb & ci.ub \\
\hline C-M. Hung et al., 2014 & -0.32 & -0.66 & 0.03 \\
S-M Wang et al., 2020 & -0.33 & -0.68 & 0.02 \\
H.M.Z. Alanazi et al., 2020 & -0.16 & -0.33 & 0.01 \\
B. Jensen et al., 2013.1 & -0.33 & -0.68 & 0.01 \\
B. Jensen et al., 2013.2 & -0.32 & -0.67 & 0.02 \\
B. Jensen et al., 2013.3 & -0.34 & -0.69 & 0.00 \\
A.J. Walker et al., 2018.1 & -0.30 & -0.65 & 0.04 \\
A.J. Walker et al., 2018.2 & -0.32 & -0.67 & 0.03 \\
Y.M. Huang et al., 2014.1 & -0.28 & -0.62 & 0.05 \\
Y.M. Huang et al., 2014.2 & -0.30 & -0.64 & 0.05 \\
E. Novak et al., 2015.1 & -0.34 & -0.69 & 0.00 \\
E. Novak et al., 2015.2 & -0.33 & -0.68 & 0.01 \\
S. Vanbecelaere et al., 2020 & -0.35 & -0.69 & -0.01 \\
E.N. Castellar et al., 2014 & -0.36 & -0.69 & -0.03 \\
M. Rocha et al., 2020 & -0.36 & -0.70 & -0.02 \\
F. Santos et al., 2021 & -0.32 & -0.67 & 0.02 \\
\hline
\end{tabular}

Table 3

Sensitivity analysis using the Leave-One-Out Method for all studies. Each line represents the results obtained excluding that study.

\begin{tabular}{rrrr}
\hline Paper & effect size & ci.lb & ci.ub \\
\hline C-M. Hung et al., 2014 & -0.11 & -0.32 & 0.11 \\
B. Jensen et al., 2013.1 & -0.13 & -0.35 & 0.09 \\
B. Jensen et al., 2013.2 & -0.12 & -0.34 & 0.10 \\
B. Jensen et al., 2013.3 & -0.14 & -0.36 & 0.08 \\
Y.M. Huang et al., 2014.1 & -0.06 & -0.23 & 0.12 \\
Y.M. Huang et al., 2014.2 & -0.08 & -0.27 & 0.12 \\
E. Novak et al., 2015.1 & -0.14 & -0.36 & 0.07 \\
E. Novak et al., 2015.2 & -0.13 & -0.35 & 0.09 \\
S. Vanbecelaere et al., 2020 & -0.16 & -0.38 & 0.06 \\
E.N. Castellar et al., 2014 & -0.17 & -0.37 & 0.04 \\
M. Rocha et al., 2020 & -0.17 & -0.38 & 0.04 \\
F. Santos et al., 2021 & -0.12 & -0.34 & 0.11 \\
\hline
\end{tabular}

Table 4

Sensitivity analysis using the Leave-One-Out Method for studies with digital intervention only. Each line represents the results obtained excluding that study.

\begin{tabular}{rrrr}
\hline$r_{\text {pre.post }}$ & $d_{p p c 2}$ & ci.lb & ci.ub \\
\hline 0.50 & -0.31 & -0.63 & 0.01 \\
0.70 & -0.32 & -0.64 & 0.01 \\
0.90 & -0.32 & -0.65 & 0.02 \\
\hline
\end{tabular}

Table 5

Sensitivity analysis varying $r_{\text {pre_post }}$ for all studies.

Regarding the sensitivity to the value of $r_{\text {pre-post }}$, Table 5 and Table 6 show how the results were robust, the overall effect for all the interventions remained the same at -0.32 while it varied insignificantly from -0.12 to -0.14 for digital games.

In order to test the robustness of the overall effect size described in figures 2 and 3 to the control data imputation, we performed a sensitivity analysis of $\delta_{C}$, starting from the value of -0.076 and using values of increasing size, therefore progressively increasing the math anxiety of the control group after the intervention to check when the overall effect size $d_{p p c 2}$ became significant. We did not perform the sensitivity analysis decreasing the value of $\delta_{C}$ since those values would have made the overall $d_{p p c 2}$ of game-based interventions even weaker, not changing the main conclusions of 


\begin{tabular}{rrrr}
\hline$r_{\text {pre.post }}$ & $d_{p p c 2}$ & ci.lb & ci.ub \\
\hline 0.50 & -0.12 & -0.33 & 0.09 \\
0.70 & -0.13 & -0.33 & 0.08 \\
0.90 & -0.14 & -0.36 & 0.08 \\
\hline
\end{tabular}

Table 6

Sensitivity analysis varying $r_{\text {pre }}$ post for studies with digital interventions.

\section{Table 7}

Sensitivity analysis for the imputed control group data. The column on the left is $\delta_{C}$, the estimated effect size of the change in math anxiety for the 4 studies with a missing control group. The other two columns show the corresponding overall $d_{p p c 2}$ effect size of all the studies (column in the centre) and for the digital studies (column on the right)

\begin{tabular}{|c|c|c|c|c|c|c|}
\hline & \multicolumn{3}{|c|}{ ALL } & \multicolumn{3}{c|}{ DIGITAL } \\
\hline$\delta_{C}$ & $d_{p p c 2}$ & ci.lb & ci.ub & $d_{p p c 2}$ & ci.lb & ci.ub \\
\hline-0.076 & -0.32 & -0.64 & 0.01 & -0.13 & -0.33 & 0.08 \\
0 & -0.34 & -0.65 & -0.03 & -0.15 & -0.34 & 0.06 \\
0.1 & -0.36 & -0.66 & -0.06 & -0.15 & -0.33 & 0.03 \\
0.2 & -0.37 & -0.68 & -0.06 & -0.15 & -0.33 & 0.03 \\
0.3 & -0.4 & -0.71 & -0.09 & -0.16 & -0.32 & 0.00 \\
0.4 & -0.42 & -0.74 & -0.1 & -0.17 & -0.31 & -0.03 \\
\hline
\end{tabular}

our analysis. Table 7 shows how the overall effect size for all the studies became significant but still small assuming that the control group did not change the mean level of math anxiety $\left(\delta_{C}=0\right)$, while the overall effect $d_{p p c 2}$ for the digital interventions became significant when we assumed that the math anxiety of the control group in the missing studies increased by an effect size of 0.4 , a value that is highly unlikely considering that the confidence interval for $\delta_{C}$ was $[-0.24,0.09]$.

\subsubsection{Evaluating publication bias}

We wondered if the studies included in this meta-analysis displayed a small studies effect, the phenomenon by which smaller studies sometimes show different, often better, treatment effects than large ones. In our study, a better treatment is represented by larger negative effect size. By looking at the forest plot of Figure 2, we note how the 4 studies with the best treatment effect were indeed small sample (less than 30 participants), while the two biggest studies (Rocha and Dondio (2021), Vanbecelaere, Van den Berghe, Cornillie, Sasanguie, Reynvoet and Depaepe (2020)) had positive effect size (and therefore math anxiety increased after the intervention). However, the rank correlation test for funnel plot asymmetry (Begg and Mazumdar (1994)) for all the studies had the following results: $\tau=-0.33, p=0.08$ therefore weakly rejecting the hypothesis of small studies effect. When we considered only digital games, we found $\tau=-0.18, p=0.46$, rejecting the hypothesis of small studies effect more decisively. In figures 4 and 5 the funnel plots respectively for all the studies and for the digital games are shown. In both of the funnel plots the trim and fill method added no hypothetical missing studies. Therefore, these tests did not provide evidence of publication bias. The adjusted effect size was slightly increased (corresponding to a smaller reduction in math anxiety).

We also note how a correction due to the presence of small studies (likely biased towards higher reduction in math anxiety) would have made the overall effect of game-based interventions even weaker, further supporting our main conclusion about the lack of efficacy of such interventions.

\subsubsection{Evaluating moderators}

The moderators for each study are listed in Table 8. Multiple experiments reported in the same paper had the same values for the moderators and therefore the table reports the moderators at study-level.

We started by testing the effect of each moderator separately. We noted how the Game Type and the Gameplay moderators coincided since all the non-digital games had a collaborative team-based gameplay and all the digital games had a single-player game mode. Therefore, the two moderators had the same effect. As shown in Table 9, two moderators were significant: the Game Type and the Gameplay moderators (coinciding and therefore treated as one moderator) and the Total time. The coefficients of the corresponding random-effect models are reported in Table 10. A non-digital game, corresponding to a collaborative game play, decreased the effect size by 0.75 , meaning that the 


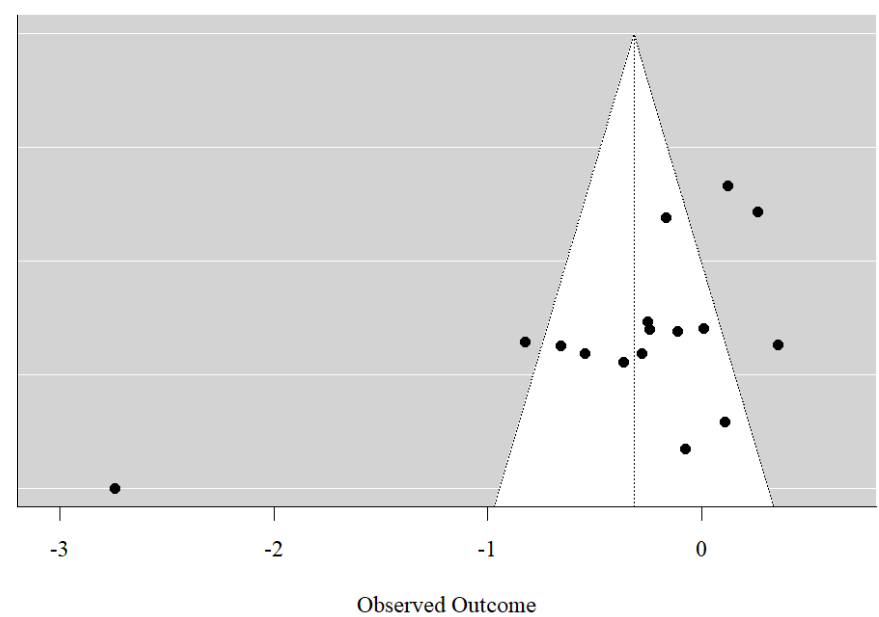

Figure 4: Funnel plot for all studies. Each black dot represents one study included in the meta-analysis. The absence of white points indicates that our analysis is not biased.

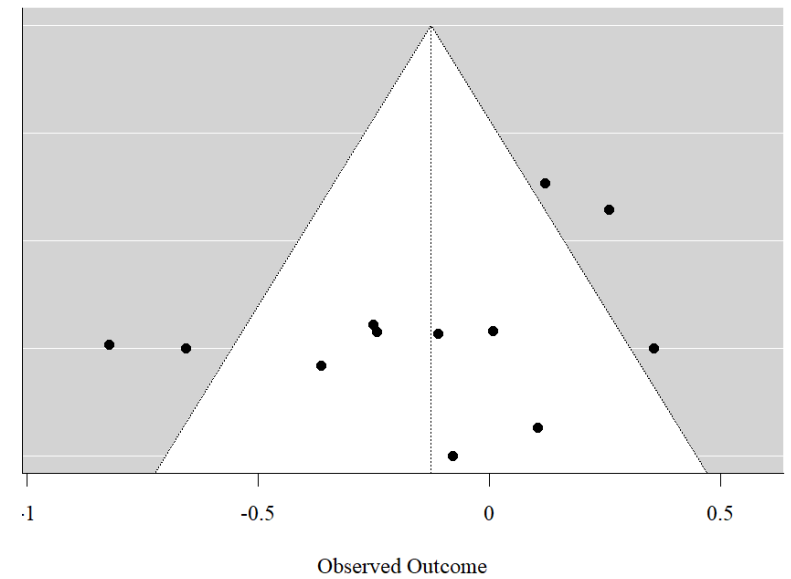

Figure 5: Funnel plot only for studies with digital interventions. Each black dot represents one study included in the meta-analysis.

intervention was more effective in reducing math anxiety. Regarding Total time, one more extra hour of play decreased the effect size by 0.09 .

We also tested the two significant predictors together as shown in Table 11. Both the predictors were significant (even if Game Type only at 0.9 level) and their coefficients were negative, suggesting how both helped to reduce math anxiety. The model with both the predictors was a better fit than the individual ones, as the $R^{2}$ increased to 43.5 from the values of 23.21 and 33.42 found in the individual models of Table 10.

\section{Discussion}

The aim of this meta-analysis was the investigation of the effect of game-based interventions to reduce math anxiety. The mean effect size of the 16 experiments considered was -0.32 with a large $95 \%$ confidence interval of $[-0.64,0.01]$. Therefore, the results suggested a small to moderate effect size not significant at the $95 \%$ level. Only 4 out of 16 experimental interventions significantly reduced math anxiety, while no significant effect was found in the other inter- 
Table 8

Moderators used in the analysis. The column type represents the type of game, either digital (D) or non-digital (ND). The column gameplay represents the gameplay mode, either single or team/collaborative $(\mathrm{T}+\mathrm{C})$

\begin{tabular}{|l|c|c|c|c|c|c|c}
\hline Author & Type & Sessions & $\begin{array}{c}\text { Time } \\
(\mathrm{mins})\end{array}$ & Gameplay & Reward & $\begin{array}{c}\text { Sophistication of } \\
\text { mechanics }\end{array}$ & $\begin{array}{c}\text { Age } \\
\text { group }\end{array}$ \\
\hline \hline Hung (2014) & D & Single & 240 & Single & More than score & School like activities & 10.5 \\
\hline Wang (2020) & ND & Single & 15 & T+C & Score & School like activities & 12.5 \\
\hline Alanazi (2020) & ND & Many & 1080 & T+C & More than score & Additional mechanics & 6.5 \\
\hline Jensen (2013) & D & Many & 180 & Single & More than score & School like activities & 11 \\
\hline Walker (2018) & ND & Many & 450 & T+C & Score & Additional mechanics & 8.5 \\
\hline Huang (2014) & D & Many & 240 & Single & Score & School like activities & 7.5 \\
\hline Novak (2015) & D & Many & 600 & Single & More than score & Additional mechanics & 20.5 \\
\hline Vanbecelaere (2020) & D & Many & 300 & Single & More than score & Additional mechanics & 6.5 \\
\hline Castellar (2014) & D & Many & NA & Single & More than score & School-like activities & 7.5 \\
\hline Rocha (2020) & D & Many & 135 & Single & More than score & School-like activities & 7.5 \\
\hline Santos (2021) & D & Many & 300 & Single & More than score & School-like activities & 8.5 \\
\hline \hline
\end{tabular}

Table 9

Effect of each moderator. Different values of heterogeneity and variability are shown. The last two columns show the result of the significance $\chi^{2}$ test and the associated p-value. Only the three moderators Game Type, Total time and Gameplay resulted significant

\begin{tabular}{|c|c|c|c|c|c|c|c|}
\hline & Moderator & $\mathrm{R}^{2}$ & $1^{2}$ & $\mathrm{H}^{2}$ & $\overline{\tau^{2}}$ & $\chi^{2}$ & p-value \\
\hline 1 & Game type & 23.21 & 89.64 & 9.65 & 0.28 & 5.08 & 0.02 \\
\hline 2 & Total time (mins) & 33.42 & 88.60 & 8.77 & 0.25 & 7.43 & 0.01 \\
\hline 3 & N.sessions & $<0.01$ & 92.49 & 13.31 & 0.41 & 0.00 & 0.96 \\
\hline 4 & Age & 0.85 & 92.01 & 12.52 & 0.42 & 1.31 & 0.25 \\
\hline 5 & Gameplay & 23.21 & 89.64 & 9.65 & 0.28 & 5.08 & 0.02 \\
\hline 6 & Reward & $<0.01$ & 92.28 & 12.95 & 0.39 & 0.32 & 0.57 \\
\hline 7 & Sophistication & $<0.01$ & 91.73 & 12.09 & 0.37 & 1.15 & 0.28 \\
\hline
\end{tabular}

Table 10

Individual random effects models for the significant moderators

\begin{tabular}{lrrrrrr}
\hline & $\beta$ & $\sigma$ & $z$ & p-value & ci lower & ci upper \\
\hline Intercept & -0.11 & 0.16 & -0.70 & 0.49 & -0.44 & 0.21 \\
Game Type: Non-digital/Game play: Collaborative & -0.75 & 0.33 & -2.25 & 0.02 & -1.40 & -0.10 \\
\hline & & & & & & \\
\hline Intercept & 0.22 & 0.23 & 0.94 & 0.34 & -0.23 & 0.67 \\
Total.time & -0.0015 & 0.0006 & -2.73 & 0.01 & -0.00 & -0.00 \\
\hline
\end{tabular}

ventions. The heterogeneity of the model was significantly high $\left(I^{2}=91 \%\right)$ confirming a high variation in the studies included and the need for a detailed sensitivity analysis. We note how previous meta-analyses in the field of gamebased interventions have shown similar heterogeneity. The recent meta-analysis by Benavides-Varela et al. (2020) on the effectiveness of game-based interventions for children with math learning disabilities included 13 experimental studies and reported a value for $I^{2}$ of $90.1 \%$.

Our leave-one-out sensitivity analysis showed how the results were robust: the overall effect size varied from -0.36 to -0.16 and only in 4 out of 16 cases the confidence level of the overall effect size was significant at $95 \%$ level. The value of -0.16 was obtained by removing the outlier study of Alanazi (2020). We also checked the sensitivity to $r_{\text {pre-post }}$, the correlation between the pre- and post-test. The overall effect size was not sensitive to $r_{\text {pre-post }}$. Regarding the sensitivity to the control group data imputation (Table 7), our results showed how a moderate effect size $d_{p p c 2}$ of about -0.4 would have been obtained only by assuming an effect size for the pre-post change in math anxiety in the control group of $\delta_{C}=0.4$, much bigger than 0.09 , the upper bound of the $95 \%$ confidence level for our estimated 


\section{Table 11}

Random effects model with both the significant moderators

\begin{tabular}{lrrrrrr}
\hline & $\beta$ & $\sigma$ & $\mathrm{z}$ & pvalue & ci_lower & ci_upper \\
\hline Intercept & 0.25 & 0.22 & 1.18 & 0.24 & -0.17 & 0.68 \\
Total.time & -0.0012 & 0.00 & -2.27 & 0.02 & -0.002 & -0.00 \\
Game Type: non-digital & -0.54 & 0.30 & -1.77 & 0.08 & -1.14 & 0.06 \\
\hline
\end{tabular}

$R^{2}=43.5, I^{2}=86.5, H^{2}=7.42, \tau^{2}=0.21, \chi^{2}=11.4$, p-value: $<0.01$

value for $\delta_{C}$. The funnel plot analysis showed no missing studies. In summary, the overall meta-analysis provided weak positive evidence on the efficacy of game-based interventions, and it cannot be concluded that game-based interventions proved to be effective in reducing math anxiety.

The results were moderated by several factors. This meta-analysis was particularly interested in investigating the effect of the interventions based on digital games. It was found that digital games had a negligible effect: the overall effect size was -0.13 with a confidence interval of $[-0.33,0.08]$, meaning that the effect size was small and not significant. Heterogeneity decreased to $68.8 \%$. The funnel plot did not detect missing studies. The sensitivity analysis showed how the results were robust, none of the overall effect sizes were significant when one study was removed or when the $r_{\text {pre-post }}$ varied. Regarding the sensitivity to control group imputation, the overall $d_{p p c 2}$ value became significant only assuming an effect size of $\delta_{C}=0.4$ for the pre-post change in math anxiety in the control group, that was statistically unlikely.

Regarding the effect of other moderators, the nature of the game (digital/non digital), the type of gameplay (collaborative vs. single-player) and the duration of the intervention were the significant moderators. Non-digital games and longer interventions resulted more effective in reducing math anxiety. Since all the non-digital games were collaborative games and all the digital ones were single-player, the effect of the collaborative gameplay could not be distinguished from the digital or non-digital nature of the games. The moderators resulted significant also when considered together (Table 11). An increase in the duration of the intervention of 1 hour decreases the effect size of about 0.07 (thus decreasing math anxiety levels post-intervention), while the collaborative nature of the game decreases the effect size by 0.54 compared to the non-collaborative gameplay. Our findings are in line with previous analysis on game-based interventions. In a meta-analysis comparing the impact of digital and non-digital games on cognitive abilities of players, Talan et al. (2020) suggested that non-digital games have higher effect size as they provide more opportunities for peer interaction and flexibility of design (Talan et al. (2020)). Furthermore, in line with previous similar studies (Sitzmann (2011), Talan et al. (2020)), longer interventions were more effective than shorter ones.

The fact that all digital games were single play poses the question if the digital nature of the games rather than their collaborative and social aspects might be responsible for the reduction in math anxiety, and if other factors, such as computer anxiety, might come into the picture and need to be controlled in the experimental design. The link between math anxiety and computer anxiety is not straightforward: a correlation was reported in Glass and Knight (1988) but not in Todman and Lawrenson (1992). However, we cannot ignore the effects that screen time can have on children in an education environment. The effects include poorer performance at school (Kates, Wu and Coryn (2018); Felisoni and Godoi (2018)), sleep problems (Twenge, Joiner, Rogers and Martin (2018)), adolescent depression and aggressive behavior (Kim, Cho and Kim (2017); Maras, Flament, Murray, Buchholz, Henderson, Obeid and Goldfield (2015)), The use of interactive screens is also linked to symptoms of ADHD, depressive symptoms and suicidal thoughts. Screen time is one of the main indicators of video game addiction (Stiglic and Viner (2019)), a disorder recently recognized by the World Health Organization. Currently, it is not well understood if educational digital games pose such risks, and further research are needed (Melo, Madariaga, Nussbaum, Heller, Bennett, Tsai and van Braak (2020)). Here we stress how games delivered via a digital device might have harmful effects if their use is not properly planned into the educational curriculum (Mercer, Kythreotis, Robinson, Stolte, George and Haywood (2017)), and it is indeed a factor to be controlled in research design.

We wonder about the possible explanations for these overall weak results and how games (especially digital) can be made more effective in reducing math anxiety.

There are a few possible explanations for these weak results. Our analysis seems to suggest that game-based interventions are more effective when games contain collaborative and interactive elements or a social aspect. On the contrary, single-player games were less effective. Therefore, a first recommendation is to design digital educational 
games able to capture the collaborative and social aspects easier to find in non-digital games. Indeed, educational digital games employing a collaborative gameplay exist, but they were not tested in the context of math anxiety.

In addition, we note that none of the games adopted by the evaluated studies was explicitly designed for tackling MA, but they were rather digital games designed for general learning or off-the-shelf games. Moreover, in at least half of the studies analysed, the effect of the intervention on MA was usually an added research question, while the core question was the impact of games on cognitive abilities.

In our opinion, placing math anxiety at the centre of the game design and the experimental process is the core issue for future research. It is paramount to understand the relationship between game features, gameplay and math anxiety. In this respect, an RCT study design might not be the only possible research methodology to be used. The typical RCT pre-post study used to test the reduction of MA after a game-based intervention often neglects the game experience of participants during such intervention. We contend that, in order for games to be effective in treating MA, it is essential to analyse how math anxious students behave while playing. It is important to measure the impact of MA on the game experience of players by analysing game data in a more systematic way in order to understand what game elements trigger anxiety and which ones promote healthy engagement. It is necessary to consider how to design the game mechanics, the mode of interactions between players, leader boards, game rewards, narrative, competition aspects and so forth considering also (or specifically) students with math anxiety.

Another plausible explanation is the way math anxiety is measured. Most scales usually target cognitive and behavioural components of MA, while physiological components are less explored. Therefore, even in non-significant studies, there is still a possibility that MA was not fully examined by the scales, which eventually could be detected by other ways. Also, math anxiety scales typically focus on anxious states in a certain interval (e.g., last month) rather than in the course of action, i.e. during the game playing. Although all MA measures were standardised, they were not designed to measure the game-related experience. In the studies analysed, participants were mainly asked about their feelings regarding studying or performing mathematics which bring memories of adverse experiences, leaning to a less positive response after games. That is different from testing participants on how mathematics becomes easier or pleasant after practising the games, meaning that such measures may not be the most appropriate for this aim. Math anxiety is not a unidimensional construct; it includes the anxiety related to being tested in mathematics, the anxiety related to learning mathematics and the anxiety experienced in daily life situations involving mathematics (Cipora et al. (2019)). MA has a complex link with performance, gender and other forms of anxiety (Cipora, Santos, Kucian and Dowker (2021)). Therefore, changes in math anxiety should be controlled by multiple individual-level factors, but none of the studies presented in this meta-analysis investigated the dependency of their results on such controlling factors and only reported overall population means. It would be interesting to know if MA is reduced in individuals with a specific profile, even when the mean math anxiety is not reduced in the overall population.

\subsection{How can digital games be more effective in reducing Math Anxiety? Ideas for future research directions}

In response to the weak results of our meta-analysis, we suggest exploring the impact of collaborative and interactive game play and developing and testing games specifically designed to deal with math anxiety. This would require an understanding of the game features that could trigger or mitigate math anxiety. But what game features look promising in treating math anxiety?

As suggested by Van Eck (2006), game features promoting a positive attitude towards mathematics could be suggested by the theory of intrinsic motivation in games (Malone (1987)), and the concept of immersive experience, advocated as the major responsible for the positive emotions during video game playing (Hoffman; Quinn (2005); Guo, Xiao, Chanyoung and Lai (2012); Nah, Eschenbrenner, Zeng, Telaprolu and Sepehr (2014)).

Intrinsic motivation is promoted by four factors: creating a sense of challenge and accomplishment, promoting curiosity, encouraging a sense of personal control and using endogenous fantasy elements. The role of endogenous fantasy elements is crucial: the game should keep the content and the fantasy aspect of the game contextually related (endogenous). That means that the math curriculum content should be embedded seamlessly in the game rather being minimally or not credibly tied to the game world. This immersive effect and endogenous fantasy are triggered through the storyline, through characters, through themed design. The large majority of games included in this meta-analysis was either puzzle-based or quiz-based and they could have failed to trigger endogenous fantasy, resulting in a digital version of the same math content that causes anxiety.

Since it is well known that MA affects more girls than boys (Rubinsten et al. (2012) Van Mier et al. (2019)), the fact that only one study (Rocha and Dondio (2021)) considered the gender variable as part of the design study and analysis 
is surprising. The use of gender-aware and inclusive design in games could be indeed a feature worth investigating in the context of math anxiety.

Game adaptivity has been indicated as a promising feature to reduce MA (Klinkenberg et al. (2011)). Adaptive games keep the level of difficulty adequate to the players and maintain their motivation higher, therefore promoting higher self-confidence and engagement. However, only the studies by Vanbecelaere et al. (2020) and Santos (2021) analysed the effect of adaptive games on MA, finding no statistically significant gap with the control group.

Another future research direction is the design of games using math anxiety as a real-time feature to adapt the game content and increase engagement. The game Math-Mind (Verkijika and De Wet (2015)) is the only study we found where MA levels are measured real-time via a BCI device and shown to the player. The idea is to motivate the player to lower these levels, since the lower the MA levels are, the more rewards the player gets. The results of this study suggest that an anxiety-aware game could benefit from measuring anxiety real-time. If a BCI device is an invasive and not scalable solution, an alternative could be to measure MA through the analysis of videos of learners playing the game, a solution that was already tested in the SCOOP! game by Isbister, Karlesky, Frye and Rao (2012). An alternative could be to measure anxiety by implicitly extrapolating MA levels from game logs, but we did not find relevant papers describing such methodology.

\section{Conclusions}

In this paper we performed a meta-analysis of the empirical evidence about the effectiveness of game-based interventions to reduce students' levels of math anxiety. We also tested the impact of a set of moderators, including the digital or non-digital nature of the games used, the type of gameplay, the age group and school level, the duration of the intervention. After performing a search for randomised controlled studies describing game-based interventions to reduce math anxiety, 16 experimental studies with a total of 686 participants described in 11 peer-reviewed articles met the selection criteria. In all the studies the participants were selected randomly and not pre-filtered based on level of math anxiety, making the findings applicable to the general population. A random effects meta-analysis indicated a small and non-significant reduction of math anxiety (mean effect size $d_{p p c 2}=-0.32, C I=[-0.67,0.02]$ ). The results were moderated by several factors. Non-digital and collaborative games were more effective, while digital games had a negligible mean effect size of $d_{p p c 2}=-0.13, C I=[-0.33,0.08]$. The effect size was moderated also by the total duration of the intervention, to the advantage of longer interventions. Moreover, game-based interventions had a greater effect on math anxiety reduction when they promoted collaborative and social interactions. Such features were present only in non-digital games, while all the digital games analysed were single-player, leaving open the question whether the reason for the reduction in math anxiety was the non-digital nature of the games rather than the gameplay.

Our recommendations include the need to reconsider the way math anxiety is measured and to develop and test games explicitly design to treat math anxiety, absent at present. This will require the investigation of the relationship between game features and math anxiety through an analysis of the behaviour of anxious and non-anxious students at play. We also suggested possible features that an anxiety-aware game could employ; digital games should include more collaborative gameplay, social aspects, features to promote intrinsic motivation, adaptability and real-time implicit measures of math anxiety.

In summary, there is little convincing empirical evidence on the impact of game-based intervention on MA levels, particularly when digital games are used. This could be explained partially by the lack of games explicitly designed to deal with math anxiety, their lack of collaborative and interactive gameplay and by the lack of understanding of the features that should be included in a game to treat MA.

\section{Limitations}

A first limitation was the inclusion in the meta-analysis of four studies without a control group. These studies could not be used directly since the absence of a control group could have positively biased their results. Our estimation of a control group was based on similar relevant studies. In one study (Huang et al. (2014)) a custom modification of the MARS scale was used, and therefore we could not find relevant studies. However, we addressed the extra variance introduced by our imputation by performing a large sensitivity analysis that did not modify the two main findings of our meta-analysis, namely that game-based interventions had a small and non-significant positive effect and digital games had a negligible effect. Conclusions should also be weighted by the number of the studies considered and the high variability found across them. The high heterogeneity is reflected by the large confidence intervals. As stated before, 
previous meta-analyses in the field of game-based interventions have shown similar heterogeneity (Benavides-Varela et al. (2020)). This variability across studies prevents strong conclusions and generalizations of the effectiveness of digital interventions for children with mathematical anxiety. The large heterogeneity is a sign of unpredictability of the treatment, but it does not invalidate the main conclusions. The forest plot of figure 2 shows how only 4 out of 16 experiments did not include zero in their confidence intervals, leaving little room for interpretations. The heterogeneity of the model considering only studies based on digital games was high but much lower than the one found for all the studies (68\% versus 91\%), meaning that digital games study presented less variations in their results and our conclusion about the lack of their efficiency is more robust.

Another source of variability was the use of different scales to measure math anxiety. The studies selected used 7 different scales. The variability was moderated by the fact that all the scales were validated tools, many of them validated considering correlation with the other scales. The analysis of the funnel plots did not reveal any missing studies nor the presence of a small study effect that nevertheless would have made our conclusions on the lack of efficacy of game-based interventions even stronger.

\section{References}

Afari, E., Aldridge, J.M., Fraser, B.J., Khine, M.S., 2013. Students' perceptions of the learning environment and attitudes in game-based mathematics classrooms. Learning Environments Research 16, 131-150.

Alanazi, H.M.N., 2020. The effects of active recreational math games on math anxiety and performance in primary school children: An experimental study. Multidisciplinary Journal for Education, Social and Technological Sciences 7, 89-112.

Alexander, L., Martray, C., 1989. The development of an abbreviated version of the mathematics anxiety rating scale. Measurement and Evaluation in counseling and development 22, 143-150.

Barroso, C., Ganley, C.M., McGraw, A.L., Geer, E.A., Hart, S.A., Daucourt, M.C., 2021. A meta-analysis of the relation between math anxiety and math achievement. Psychological Bulletin 147, 134.

Begg, C.B., Mazumdar, M., 1994. Operating characteristics of a rank correlation test for publication bias. Biometrics , $1088-1101$.

Beilock, S.L., Gunderson, E.A., Ramirez, G., Levine, S.C., 2010. Female teachers' math anxiety affects girls' math achievement. Proceedings of the National Academy of Sciences 107, 1860-1863.

Benavides-Varela, S., Callegher, C.Z., Fagiolini, B., Leo, I., Altoè, G., Lucangeli, D., 2020. Effectiveness of digital-based interventions for children with mathematical learning difficulties: a meta-analysis. Computers \& Education 157, 103953.

Bicer, A., Perihan, C., Lee, Y., 2020. A meta-analysis: The effects of cbt as a clinic-\& school-based treatment on students' mathematics anxiety. International Electronic Journal of Mathematics Education 15.

Byun, J., Joung, E., 2018. Digital game-based learning for k-12 mathematics education: A meta-analysis. School Science and Mathematics 118, 113-126.

Carey, E., Hill, F., Devine, A., Szúcs, D., 2017. The modified abbreviated math anxiety scale: A valid and reliable instrument for use with children. Frontiers in psychology 8,11 .

Carmo, J., Figueiredo, R., 2005. Aprendizagem, emoção e ansiedade matemática: indícios e vestígios de histórias de punição e fracasso no ensino da matemática. Revista Trilhas (UNAMA) 7, 85-93.

Chiu, L.H., Henry, L.L., 1990. Development and validation of the mathematics anxiety scale for children. Measurement and evaluation in counseling and development .

Cipora, K., Artemenko, C., Nuerk, H.C., 2019. Different ways to measure math anxiety, in: Mathematics Anxiety. Routledge, pp. $20-41$.

Cipora, K., Santos, F.H., Kucian, K., Dowker, A., 2021. Mathematics anxiety-where are we and where shall we go? .

Clark, D.B., Tanner-Smith, E.E., Killingsworth, S.S., 2016. Digital games, design, and learning: A systematic review and meta-analysis. Review of Educational Research 86, 79-122. URL: https://doi.org/10.3102/0034654315582065, doi:10.3102/0034654315582065, arXiv: https://doi.org/10.3102/0034654315582065. pMID: 26937054.

Cohen, J., 2013. Statistical power analysis for the behavioral sciences. Academic press.

Dondio, P., Gusev, V., Santos, F., Rocha, M., 2021. Do games reduce maths anxiety? a systematic review of the effect of game-based learning on maths anxiety, in: Proceedings of the 15th European Conference on Games Based Learning, Brighton, UK, September 23-24. pp. 284-292.

Dowker, A., Sarkar, A., Looi, C.Y., 2016. Mathematics anxiety: What have we learned in 60 years? Frontiers in psychology 7, 508.

Duval, S., Tweedie, R., 2000. Trim and fill: a simple funnel-plot-based method of testing and adjusting for publication bias in meta-analysis. Biometrics 56, 455-463.

Fadda, D., Pellegrini, M., Vivanet, G., Zandonella Callegher, C., 2022. Effects of digital games on student motivation in mathematics: A metaanalysis in k-12. Journal of Computer Assisted Learning 38, 304-325.

Felisoni, D.D., Godoi, A.S., 2018. Cell phone usage and academic performance: An experiment. Computers \& Education 117, $175-187$.

Fennema, E., Sherman, J.A., 1976. Fennema-sherman mathematics attitudes scales: Instruments designed to measure attitudes toward the learning of mathematics by females and males. Journal for research in Mathematics Education 7, 324-326.

Garris, R., Ahlers, R., Driskell, J.E., 2002. Games, motivation, and learning: A research and practice model. Simulation \& gaming $33,441-467$.

Gil-Doménech, D., Berbegal-Mirabent, J., 2019. Stimulating students' engagement in mathematics courses in non-stem academic programmes: A game-based learning. Innovations in Education and Teaching International 56, 57-65.

Gil-Doménech, D., Berbegal-Mirabent, J., Borsot, G., 2017. Enhancing business students' skills through a cross-curricular activity, in: Proceedings of the 3rd International Conference on Higher Education Advances, Editorial Universitat Politècnica de València. pp. $284-292$. 


\section{Do Games Reduce Math Anxiety?}

Girard, C., Ecalle, J., Magnan, A., 2013. Serious games as new educational tools: how effective are they? a meta-analysis of recent studies. Journal of computer assisted learning 29, 207-219.

Glass, C.R., Knight, L.A., 1988. Cognitive factors in computer anxiety. Cognitive therapy and research 12, 351-366.

Guo, Z., Xiao, L., Chanyoung, S., Lai, Y., 2012. Flow experience and continuance intention toward online learning: an integrated framework .

Hill, F., Mammarella, I.C., Devine, A., Caviola, S., Passolunghi, M.C., Szúcs, D., 2016. Maths anxiety in primary and secondary school students: Gender differences, developmental changes and anxiety specificity. Learning and Individual Differences 48, 45-53.

Hoffman, D.L., . novak tp (1995). Marketing in Hipermedia Computer-Mediated Enviroment: Conceptual Foundations .

Homer, B.D., Raffaele, C., Henderson, H., 2020. 2 games as playful learning: Implications of developmental theory for game-based learning. Handbook of Game-Based Learning, 25.

Huang, Y.M., Huang, S.H., Wu, T.T., 2014. Embedding diagnostic mechanisms in a digital game for learning mathematics. Educational Technology Research and Development 62, 187-207.

Hung, C.M., Huang, I., Hwang, G.J., 2014. Effects of digital game-based learning on students' self-efficacy, motivation, anxiety, and achievements in learning mathematics. Journal of Computers in Education 1, 151-166.

Hunsley, J., Flessati, S.L., 1988. Gender and mathematics anxiety: The role of math-related experiences and opinions. Anxiety Research 1, 215-224.

Isbister, K., Karlesky, M., Frye, J., Rao, R., 2012. Scoop! a movement-based math game designed to reduce math anxiety, in: CHI'12 extended abstracts on human factors in computing systems, pp. 1075-1078.

Juul, J., 2010. The game, the player, the world: Looking for a heart of gameness. Plurais Revista Multidisciplinar 1.

Käser, T., Baschera, G.M., Kohn, J., Kucian, K., Richtmann, V., Grond, U., Gross, M., von Aster, M., 2013. Design and evaluation of the computerbased training program calcularis for enhancing numerical cognition. Frontiers in psychology 4, 489.

Kates, A.W., Wu, H., Coryn, C.L., 2018. The effects of mobile phone use on academic performance: A meta-analysis. Computers \& Education $127,107-112$.

Ke, F., 2006. Classroom goal structures for educational math game application .

Kim, E., Cho, I., Kim, E.J., 2017. Structural equation model of smartphone addiction based on adult attachment theory: Mediating effects of loneliness and depression. Asian nursing research 11, 92-97.

Klinkenberg, S., Straatemeier, M., van der Maas, H.L., 2011. Computer adaptive practice of maths ability using a new item response model for on the fly ability and difficulty estimation. Computers \& Education 57, 1813-1824.

Ku, C.H., Kwak, M., Yurov, K., Yurova, Y., 2014a. A study of the influence of gaming behavior on academic performance of it college students .

Ku, O., Chen, S.Y., Wu, D.H., Lao, A.C., Chan, T.W., 2014b. The effects of game-based learning on mathematical confidence and performance: High ability vs. low ability. Journal of Educational Technology \& Society 17, 65-78.

Levy, H.E., Fares, L., Rubinsten, O., 2021. Math anxiety affects females' vocational interests. Journal of Experimental Child Psychology 210, 1-16. doi:https://doi.org/10.1016/j.jecp.2021.105214.

Linehan, C., Kirman, B., Lawson, S., Chan, G., 2011. Practical, appropriate, empirically-validated guidelines for designing educational games, in: Proceedings of the SIGCHI Conference on Human Factors in Computing Systems, Association for Computing Machinery, New York, NY, USA. p. 1979-1988. URL: https://doi.org/10.1145/1978942.1979229, doi:10.1145/1978942.1979229.

Linsen, S., Maertens, B., Husson, J., Van den Audenaeren, L., Wauters, J., Reynvoet, B., De Smedt, B., Verschaffel, L., Elen, J., 2015. Design of the game-based learning environment "dudeman \& sidegirl: Operation clean world," a numerical magnitude processing training, in: Describing and studying domain-specific serious games. Springer, pp. 9-26.

Lowrie, T., Jorgensen, R., 2015. Digital games and learning: What's new is already old?, in: Lowrie, T., Jorgensen, R. (Eds.), Digital Games and Mathematics Learning. Springer, Dordrecht, the Netherlands, pp. 1-9.

Luttenberger, S., Wimmer, S., Paechter, M., 2018. Spotlight on math anxiety. Psychology research and behavior management 11, 311.

Ma, X., 1999. A meta-analysis of the relationship between anxiety toward mathematics and achievement in mathematics. Journal for research in mathematics education $30,520-540$.

Malone, T.W., 1987. Making learning fun: A taxonomic model of intrinsic motivations for learning. Conative and affective process analysis .

Maras, D., Flament, M.F., Murray, M., Buchholz, A., Henderson, K.A., Obeid, N., Goldfield, G.S., 2015. Screen time is associated with depression and anxiety in canadian youth. Preventive medicine 73, 133-138.

McMullan, M., Jones, R., Lea, S., 2012. Math anxiety, self-efficacy, and ability in british undergraduate nursing students. Research in nursing \& health $35,178-186$

Melo, C., Madariaga, L., Nussbaum, M., Heller, R., Bennett, S., Tsai, C.C., van Braak, J., 2020. Educational technology and addictions. Computers and Education 145, 103730.

Mercer, T.G., Kythreotis, A.P., Robinson, Z.P., Stolte, T., George, S.M., Haywood, S.K., 2017. The use of educational game design and play in higher education to influence sustainable behaviour. International Journal of Sustainability in Higher Education

Moher, D., Shamseer, L., Clarke, M., Ghersi, D., Liberati, A., Petticrew, M., Shekelle, P., Stewart, L.A., 2015. Preferred reporting items for systematic review and meta-analysis protocols (prisma-p) 2015 statement. Systematic reviews 4, 1-9.

Morris, S.B., 2008. Estimating effect sizes from pretest-posttest-control group designs. Organizational research methods 11, 364-386.

Nah, F.F.H., Eschenbrenner, B., Zeng, Q., Telaprolu, V.R., Sepehr, S., 2014. Flow in gaming: literature synthesis and framework development. International Journal of Information Systems and Management 1, 83-124.

Namkung, J.M., Peng, P., Lin, X., 2019. The relation between mathematics anxiety and mathematics performance among school-aged students: A meta-analysis. Review of Educational Research 89, 459-496.

Novak, E., Tassell, J., 2015. Using video game play to improve education-majors' mathematical performance: An experimental study. Computers in Human Behavior 53, 124-130.

Quinn, R.W., 2005. Flow in knowledge work: High performance experience in the design of national security technology. Administrative science quarterly 50, 610-641.

Ramirez, G., Chang, H., Maloney, E.A., Levine, S.C., Beilock, S.L., 2016. On the relationship between math anxiety and math achievement in early 


\section{Do Games Reduce Math Anxiety?}

elementary school: The role of problem solving strategies. Journal of experimental child psychology 141, 83-100.

Ramirez, G., Gunderson, E.A., Levine, S.C., Beilock, S.L., 2013. Math anxiety, working memory, and math achievement in early elementary school. Journal of Cognition and Development 14, 187-202.

Rocha, M., Dondio, P., 2021. Effects of a videogame in math performance and anxiety in primary school. International Journal of Serious Games $8,45-70$.

Rothstein, H.R., Sutton, A.J., Borenstein, M., 2006. Publication bias in meta-analysis: Prevention, assessment and adjustments. John Wiley \& Sons.

Rubinsten, O., Bialik, N., Solar, Y., 2012. Exploring the relationship between math anxiety and gender through implicit measurement. Frontiers in Human Neuroscience 6, 279.

Santos, F.H., 2021. Calcularis efficacy in children with developmental dyscalculia: Testing a shorter protocol. .

Sitzmann, T., 2011. A meta-analytic examination of the instructional effectiveness of computer-based simulation games. Personnel psychology 64 , 489-528.

Skelton, R., Atkinson, C., 2014. Increasing children's working memory capacity in schools: Preliminary evaluation of a collaborative card-based programme .

Stiglic, N., Viner, R.M., 2019. Effects of screentime on the health and well-being of children and adolescents: a systematic review of reviews. BMJ open 9, e023191.

Stoet, G., Bailey, D.H., Moore, A.M., Geary, D.C., 2016. Countries with higher levels of gender equality show larger national sex differences in mathematics anxiety and relatively lower parental mathematics valuation for girls. PloS one 11, e0153857.

Talan, T., Doğan, Y., Batdı, V., 2020. Efficiency of digital and non-digital educational games: A comparative meta-analysis and a meta-thematic analysis. Journal of Research on Technology in Education 52, 474-514. URL: https://doi.org/10.1080/15391523.2020.1743798, doi:10.1080/15391523.2020.1743798, arXiv: https://doi.org/10.1080/15391523.2020.1743798.

Team, R.C., et al., 2018. R: a language and environment for statistical computing, version 3.5. 1. Vienna, Austria: R Foundation for Statistical Computing .

Todman, J., Lawrenson, H., 1992. Computer anxiety in primary schoolchildren and university students. British Educational Research Journal 18 , 63-72.

Twenge, J.M., Joiner, T.E., Rogers, M.L., Martin, G.N., 2018. Increases in depressive symptoms, suicide-related outcomes, and suicide rates among us adolescents after 2010 and links to increased new media screen time. Clinical Psychological Science 6, 3-17.

Van Eck, R., 2006. The effect of contextual pedagogical advisement and competition on middle-school students' attitude toward mathematics using a computer-based simulation game. Journal of Computers in Mathematics and Science Teaching 25, 165-195.

Van Mier, H.I., Schleepen, T.M., Van den Berg, F.C., 2019. Gender differences regarding the impact of math anxiety on arithmetic performance in second and fourth graders. Frontiers in psychology 9, 2690.

Vanbecelaere, S., Van den Berghe, K., Cornillie, F., Sasanguie, D., Reynvoet, B., Depaepe, F., 2020. The effects of two digital educational games on cognitive and non-cognitive math and reading outcomes. Computers \& Education 143, 103680.

Vandercruysse, S., Maertens, M., Elen, J., 2015. Description of the educational math game "monkey tales: The museum of anything", in: Describing and Studying Domain-Specific Serious Games. Springer, pp. 27-43.

Vazquez, F.L., Otero, P., García-Casal, J.A., Blanco, V., Torres, A.J., Arrojo, M., 2018. Efficacy of video game-based interventions for active aging. a systematic literature review and meta-analysis. PloS one 13, e0208192.

Verkijika, S.F., De Wet, L., 2015. Using a brain-computer interface (bci) in reducing math anxiety: Evidence from south africa. Computers \& Education 81, 113-122.

Viechtbauer, W., 2010. Conducting meta-analyses in $\mathrm{r}$ with the metafor package. Journal of statistical software 36, 1-48.

Vogel, J.J., Vogel, D.S., Cannon-Bowers, J., Bowers, C.A., Muse, K., Wright, M., 2006. Computer gaming and interactive simulations for learning: A meta-analysis. Journal of Educational Computing Research 34, 229-243.

Wouters, P., Van Nimwegen, C., Van Oostendorp, H., Van Der Spek, E.D., 2013. A meta-analysis of the cognitive and motivational effects of serious games. Journal of educational psychology 105, 249.

Wu, S., Amin, H., Barth, M., Malcarne, V., Menon, V., 2012. Math anxiety in second and third graders and its relation to mathematics achievement. Frontiers in psychology 3, 162 .

Zhou, C., Occa, A., Kim, S., Morgan, S., 2020. A meta-analysis of narrative game-based interventions for promoting healthy behaviors. Journal of health communication $25,54-65$. 


\section{Supplemental material for the paper "Do Games Reduce Maths Anxiety? A meta-analysis"}

This document provides a description of the supplemental material for the paper: Do Games Reduce Math Anxiety? A meta-analysis. The purpose of the study was to meta-analyze the effectiveness of game-based interventions to reduce students' level of math anxiety. The document provides supplemental data and details about the statistical analyses performed in the meta-analysis, including the list of relevant studies used to impute missing data for the studies without a control group and further sensitivity analyses.

\section{Literature Search and Data Extraction}

\subsection{Queries}

The section contains the detailed query submitted to each of the electronic databases queried for the study. For databases returning less than 30 results we relaxed the use of keywords to increase the chance of collecting relevant studies.

\section{Database: ERIC (Educational Resource Information Center)}

Date: 27th January 2022

Query: ("maths anxiety" OR "math anxiety" OR "mathematics anxiety") AND (game OR DGBL)

Results: 35

\section{Elsevier Scopus}

Date: 27th January 2022

Query: ALL ( ( "math anxiety" OR "mathematics anxiety" ) AND ( game OR gbl OR dgbl ) AND ( "effect size" OR rct OR ( "post-test" AND "pre-test" ) OR "control group" ))

Results: 146

\section{Proquest Dissertations and Theses}

Date: 27th January 2022

Query: ("maths anxiety" OR "math anxiety" OR "mathematics anxiety" ) AND ( "game-based learning" OR DGBL) AND ( "effect size" OR rct OR "post-test" AND "pre-test" OR "control group" ) )

Results: 111

\section{Google Scholar}

Date: 27th January 2022

Query: ("maths anxiety" OR "math anxiety" OR "mathematics anxiety" ) AND (game OR DGBL OR "gamebased learning") AND ((pre-test AND post-test) OR "effect size" OR "control group")

Results: 895

\subsection{Data Extraction Form}

The variables collected for each study are described in table S1.

\section{Statistical Analysis: the $d_{p p c 2}$ estimate}

The Pretest-Posttest-Control design (PPC) is a useful framework for evaluating the effect of a treatment. In the PPC design, participants are assigned to treatment or control conditions and the outcomes of interest are measured both before and after the treatment has been administered. The effect size that quantifies the effect of the treatment in 


\section{Table S1}

The table shows the structure of the database table where data from each study was collected

\begin{tabular}{|c|c|}
\hline Field & Description \\
\hline \multicolumn{2}{|c|}{ Bibliographical information } \\
\hline ID & unique number of each study \\
\hline Authors & List of authors for the study \\
\hline PubYear & Year of publication \\
\hline Journal & $\begin{array}{l}\text { Name of the journal, conference, book or University repository where the } \\
\text { study was published }\end{array}$ \\
\hline Publisher & Name of the publisher \\
\hline \multicolumn{2}{|l|}{ Study Metadata } \\
\hline Study Design & experiemntal, quasi-experimental \\
\hline Control Group & YES / NO \\
\hline Selection Method & How participants were selected \\
\hline Age group & Age group of participants \\
\hline School grade & School grade of participants \\
\hline Control Group Activity & Activity of the control group (traditional learning, business as usual...) \\
\hline \multicolumn{2}{|l|}{ Game metadata } \\
\hline Game Name & Name of the game \\
\hline Year & Year the game was published \\
\hline \multicolumn{2}{|c|}{ Game Intervention metadata } \\
\hline Weeks & number of weeks \\
\hline Session & number of weekly sessions \\
\hline Duration & Duration (in minutes) of each session \\
\hline Gameplay & $\begin{array}{l}\text { Gameplay of the game (single player, multi-player, collaborative, team col- } \\
\text { laborative) }\end{array}$ \\
\hline Aligned to Curriculum & Is the game content aligned to math curriculum? \\
\hline Sophistication & If the game mechanics include only game-like activity or more than that \\
\hline Reward & $\begin{array}{l}\text { If the reward system is represented only by the score in the game or some- } \\
\text { thing more than the score (badges, in game coins...) }\end{array}$ \\
\hline \multicolumn{2}{|c|}{ Math Anxiety instrument } \\
\hline Name & Instrument name \\
\hline Reference & Reference to the paper that introduced the scale \\
\hline Items & Number of items \\
\hline Range & Score range \\
\hline Direction & If higher score represents higher anxiety or not \\
\hline \multicolumn{2}{|c|}{ For the control group (if present) and each experimental group collect the following: } \\
\hline Size (pre) & number of participants in the group (pre-test) \\
\hline Male (pre) & number of male participants in the group (pre-test) \\
\hline MA Mean (pre) & mean value of math anxiety in the pre-test \\
\hline MA SD (pre) & standard deviation of math anxiety in the pre-test \\
\hline
\end{tabular}

a PPC design is defined as the difference between the standardized mean change for the treatment and control groups:

$$
\Delta=\delta_{t}-\delta_{c}=\frac{\left(\mu_{T, p o s t}-\mu_{T, p r e}\right)-\left(\mu_{C, p o s t}-\mu_{C, p r e}\right)}{\sigma}
$$

where $\mu_{T, p r e}$ and $\mu_{T, p o s t}$ are respectively the means for the treatment population in the pre-test and in the post-test, and $\mu_{C \text {,pre }}$ and $\mu_{C \text {,post }}$ are respectively the means for the control population in the pre-test and in the post-test. Under the assumption of normal distribution and homogeneity of variance, we can define $\sigma^{2}$ as the common variance for the two populations.

In the PPC design, treatment and control groups can be assumed to be randomly sampled from two populations, as the PPC design allows researchers to control for pre-existing differences. Morris (2008) evaluated different methods to estimate the effect size in a PPC design based on the following criteria: 1) the effect size estimate should be unbiased; 2) among unbiased estimates, the most precise effect size should be selected; 3) the distribution of the effect size 
must be known; 4) effect size should be robust to violations of assumptions (i.e., normal distribution and homogeneity of variance). Morris (2008) suggested the $d_{p p c 2}$ as the favourite effect size estimate in terms of bias, precision, and robustness to heterogeneity of variance. The $d_{p p c 2}$ is defined as the mean pre-post change in the treatment group minus the mean pre-post change in the control group, divided by the pooled pre-test standard deviation,

$$
d_{p p c 2}=c_{p} \frac{\left(M_{T, p o s t}-M_{T, p r e}\right)-\left(M_{C, p o s t}-M_{C, p r e}\right)}{S D_{\text {pooled }, p r e}}
$$

where $M_{p r e, T}, M_{T, p o s t}$ and $M_{C, p r e}, M_{C, p o s t}$ are respectively the pre, post mean scores of the treatment group and the pre, post mean scores of the control group. $S D_{\text {pooled,pre }}$ is the pooled pre-test standard deviation, computed considering only the pre-test standard deviations and the samples size $\left(n_{T}\right.$ and $\left.n_{C}\right)$ of the two groups,

$$
S D_{\text {pooled,pre }}=\sqrt{\frac{\left(n_{T}-1\right) S D_{T, p r e}^{2}+\left(n_{C}-1\right) S D_{C, p r e}^{2}}{n_{T}+n_{C}-2}}
$$

and $c_{p}$ is a bias adjustment for small sample size that can be approximated by

$$
c_{p}=1-\frac{3}{4\left(n_{T}+n_{C}-2\right)-1}
$$

\section{Plan and execution of the meta-analysis}

The analysis was conducted with the software $\mathrm{R}$ (Team et al. (2018)). The random-effects model was conducted using the restricted maximum likelihood method with the R package metafor (Viechtbauer (2010)).

The heterogeneity between studies was analysed through inspection of forest plots. To investigate the robustness of the results, we ran three sensitivity analyses. First, we used the Leave-One-Out method to evaluate how results would change if studies were excluded one at time from the analysis. Substantial changes when a single study is removed are interpreted as lack of homogeneity and unreliable results (Viechtbauer (2010)). Secondly, we evaluated our results when different values are used for the $r_{\text {pre-post }}$ coefficient, representing the correlation between the pre- and post- math anxiety test. Thirdly, we performed a sensitivity analysis on the control group data imputation, by changing the mean pre-post math anxiety change in the imputed control groups. Publication bias was assessed using the funnel plot with the trim-and-fill method (Duval and Tweedie (2000); Halpern, Berlin, Rothstein, Sutton and Borenstein (2005)).

A further sensitivity analysis (not included in the main text of the paper) was performed to test the sensitivity of the overall results to the choice of keeping multiple experiments from the same study separated versus merging the different experimental groups together.

The role of possible moderators was examined using mixed-effects meta-regression models, the moderators were included as a fixed effects and were tested using Wald's chi-square Viechtbauer (2010).

\subsection{Estimation of the control group}

Four out of ten studies did not have a control group. For these studies, control group data were estimated. Our strategy was to use control group data from similar relevant studies describing interventions to reduce MA, and to perform a large sensitivity analysis to account for the variance introduced by the imputation process.

In order to compute $d_{p p c 2}$ for the studies with no control group, equation (2) required to estimate $M_{p r e, C}, M_{p o s t, C}$ and $S D_{\text {pre, } C}$ (used in the computation of the pooled standard deviation $S D_{\text {pooled,pre }}$ ). We refer to the imputed values for each of the missing studies as $M_{\text {pre,C }}^{I}, M_{\text {post }, C}^{I}$ and $S D_{\text {pre,C }}^{I}$

\subsubsection{Imputation of the pre-mean and pre-standard deviation}

The pre-values $M_{\text {pre,C }}^{I}$ and $S D_{\text {pre,C }}^{I}$ were pooled from studies reporting measures of math anxiety collected either before an intervention or in studies with no intervention, such as maths anxiety surveys or studies used to validate a scale. More specifically, for each study with a missing control group the inclusion criteria for relevant studies were: (1) a peer-review study reporting math anxiety measurements, (2) math anxiety was collected using the same scale as the study with the missing control group, (3) math anxiety was measured before the intervention or (4) measured in a study with no intervention and (5) the study was not included in this meta-analysis. The assumption is that values 
collected before an intervention or in a study without any intervention can be used. The studies already included in our meta-analysis were excluded to avoid double counting.

Table S2 shows the list of studies used to pool the pre-mean and pre-standard deviation for the missing studies grouped by the math anxiety scale used in the studies. For the FEMA scale we included a pool of 15 groups from 6 studies, for a total of 2003 participants. For the mAMAS scale we included the original study by Carey, Hill, Devine and Szúcs (2017) that introduced and validated the scale with a sample of more than 1700 children. For the SEMA scale we included the original studies by Wu, Amin, Barth, Malcarne and Menon (2012) and Wu, Willcutt, Escovar and Menon (2014) that introduced and validated the scale.

The paper by Hung, Huang and Hwang (2014) used a customized version of the MARS scale, and therefore it was not possible to find relevant data and our only possibility was to use the pre-values of the two experimental groups reported in the paper. The extra variance introduced was dealt with the sensitivity analysis described in Table 7 in the text of the main paper.

For each group of studies, mean and standard deviations were pooled with the usual formulae (equations 5 and 6), where $N_{T O T}$ is the sum of the sample size for all the relevant studies and $n$ is the number of studies:

$$
\begin{aligned}
\mu_{\text {pooled }} & =\frac{\sum_{i=1}^{n} \mu_{i} N_{i}}{N_{T O T}} \\
\sigma_{\text {pooled }} & =\sqrt{\frac{\sum_{i=1}^{n}\left(N_{i}-1\right) \sigma_{i}^{2}}{N_{T O T}-n}}
\end{aligned}
$$

\subsubsection{Imputation of the post-mean}

Regarding the imputation of the post mean value $M_{p o s t, C}^{I}$, it was obtained from the values of $M_{p r e, C}^{I}$ and $S D_{\text {pre,C }}^{I}$ shown in Table $\mathrm{S} 2$ and by estimating the expected change in maths anxiety in a control group after the intervention on the experimental group is done. We collected a second set of relevant studies (table S3) describing an intervention to reduce maths anxiety and including a control group in their design. The inclusion criteria for this second set of similar studies were as follows: RCT studies where (1) maths anxiety was the dependent variable, (2) the participants were students, (3) the study was not part of this meta-analysis, (4) the scale used to measure math anxiety was one of the scales used in the 4 studies with the missing control group and (5) the type of control used was traditional learning or no intervention.

For each of the selected studies we computed the mean pre-post change $\delta_{C}$ represented by the following formula:

$$
\delta_{C}=\frac{\mu_{\text {post }, C}-\mu_{\text {pre }, C}}{\sigma_{\text {pre }, C}}
$$

where $\mu_{\text {post }, C}, \mu_{\text {pre,C }}$ and $\sigma_{\text {pre, } C}$ were the pre- and post- means and the pre- standard deviation of MA values for each relevant study. The overall mean value for $\delta_{C}$ was computed with a random effects model. Finally, a value for $M_{\text {post }, C}^{I}$ was obtained with the formula $M_{\text {post }, C}^{I}=M_{p r e, C}^{I}+\delta_{C} S D_{p r e, C}^{I}$.

The results of the imputation process are reported in Table S5, where the imputed values are written in bold. We note how all the imputed means are less than $0.2 \sigma$ far from the observed means for the corresponding experimental groups.

After the meta-analysis was performed, a large sensitivity analysis on the imputed data were conducted to account for the extra variance introduced by the process and to verify at what values the results of the meta-analysis changed significantly. The results of this sensitivity analysis are reported in table 7 in the main text of the paper.

A second imputation strategy could have been to estimate $\delta_{C}$ in the same way, and then approximate the $d_{p p c 2}$ by subtracting $\delta_{C}$ from the effect size of the experimental group as in equation (2). This strategy relies on a more relaxed assumption that the standard deviations of the control and experimental groups are the same. The results of the meta-analysis using this second approximations did not change significantly; the overall effect size was -0.31 .

\subsection{Treating multiple experimental groups from the same study}

Five studies included more than one experimental group. In order to be included in the meta-analysis, each experimental group had to (1) describe a game-based intervention, (2) use a distinct set of participants and (3) use a 
Table S2

The list of studies used to pool the values for the pre-mean and pre-standard deviation for the studies with no control group.

\begin{tabular}{|c|c|c|c|c|}
\hline $\mathrm{N}$ & Study & Mean & SD & $\mathrm{N}$ \\
\hline 1 & Lim and Chapman (2013) & 3.23 & 1.10 & 254 \\
\hline 2 & Lim and Chapman (2013) & 3.22 & 1.11 & 220 \\
\hline 3 & Mkhize and Maistry (2017) & 3.08 & 0.95 & 255 \\
\hline 4 & Reavis (1987) & 2.97 & 1.00 & 136 \\
\hline 5 & Reavis (1987) & 3.00 & 0.86 & 136 \\
\hline 6 & Reavis (1987) & 3.33 & 0.75 & 135 \\
\hline 7 & Kaur, Wong and Yee (2009) & 2.78 & 0.87 & 621 \\
\hline 8 & Thompson, Wylie and Hanna (2016) & 2.92 & 0.83 & 41 \\
\hline 9 & Thompson et al. (2016) & 3.17 & 1.06 & 31 \\
\hline 10 & Thompson et al. (2016) & 3.16 & 0.92 & 37 \\
\hline 11 & Thompson et al. (2016) & 3.11 & 0.87 & 29 \\
\hline 12 & Thompson et al. (2016) & 3.01 & 0.78 & 37 \\
\hline 13 & Thompson et al. (2016) & 2.93 & 0.90 & 22 \\
\hline 14 & Thompson et al. (2016) & 2.74 & 0.76 & 26 \\
\hline \multirow[t]{2}{*}{15} & Thompson et al. (2016) & 2.73 & 0.76 & 23 \\
\hline & Pooled (FEMA) & 3.01 & 0.94 & 2003 \\
\hline 1 & Huang, Huang and Wu (2014) & 26.00 & 2.79 & 29 \\
\hline \multirow[t]{2}{*}{2} & Huang et al. (2014) & 26.40 & 2.89 & 27 \\
\hline & Pooled (custom scale adapted from MARS) & 26.19 & 2.84 & 56 \\
\hline 1 & Carey et al. (2017) & 19.67 & 7.65 & 1746 \\
\hline 2 & Passolunghi, De Vita and Pellizzoni (2020) & 19.97 & 5.99 & 72 \\
\hline 3 & Jamieson, Peters, Greenwood and Altose (2016) & 20.02 & 8.10 & 45 \\
\hline \multirow[t]{2}{*}{4} & Pierpaolo Dondio (2021) & 20.49 & 6.98 & 112 \\
\hline & Pooled (mAMAS) & 19.74 & 7.65 & 1975 \\
\hline 1 & Wu et al. (2012) & 34.36 & 11.61 & 162 \\
\hline 2 & Wu et al. (2014) & 34.34 & 10.90 & 256 \\
\hline 3 & Young, Wu and Menon (2012) & 31.80 & 7.60 & 46 \\
\hline \multirow[t]{2}{*}{4} & Wright (2017) & 19.27 & 14.74 & 59 \\
\hline & Pooled (SEMA) & 32.42 & 11.38 & 523 \\
\hline
\end{tabular}

sufficiently different game. Condition (3) was introduced to decide whether to merge or keep distinct the various experimental groups. If condition (3) was not satisfied, the experimental groups were merged together.

Regarding each specific study, the paper by Novak and Tassell (2015) had two groups playing two completely different sets of games (AVG vs. non-AVG) by a distinct set of players and they were kept separated. The same situation applied to the study by Walker (2018), where two distinct set of players played different games: one group played a set of non-digital math games while the other group play the non-digital card game MeeMo. In the studies by Huang et al. (2014) and Jansen, Louwerse, Straatemeier, Van der Ven, Klinkenberg and Van der Maas (2013), distinct set of players played different version of the same game. However, we judged the experimental conditions different enough to keep the groups separated. In Huang et al. (2014) the difference between the two experimental groups was the presence of a game feedback and a diagnostic mechanism that could have greatly influenced the game experience and performance of players. In Jansen et al. (2013) the difference was the difficulty levels at which the digital-game Math Garden was played. that implied different type of quizzes and content in the game. Regarding the study by Santos (2021), the two experimental groups played the same game, but one group played a baseline version and the second group an adaptive version. After contacting the author, based on her suggestions we decided to merge the two experimental groups together since the experimental conditions were considered too close.

However, our choices had an impact on the variance introduced in the meat-analysis and they can be questioned and they. In general, with the exception of Santos (2021), we considered that each experimental group received a 
Table S3

The list of studies used to estimate the value of $\delta_{C}$. Below the table the result of the random-effect model for the estimation of $\delta_{C}$ is shown

\begin{tabular}{rlllllllll}
\hline & Study & $\mu_{\text {pre }}$ & $\sigma_{\text {pre }}$ & $\mu_{\text {post }}$ & $\sigma_{\text {post }}$ & $\mathrm{N}$ & $\mathrm{d}$ & var & Type of Control \\
\hline 1 & Moliner et al. (2020) & 2.22 & 0.59 & 2.19 & 0.52 & 210 & -0.059 & 0.003 & Traditional Learning \\
2 & Ruark (2019) & 25.18 & 7.17 & 23.09 & 7.48 & 22 & -0.28 & 0.027 & Passive (no intervention) \\
3 & Hines (2011) & 209.3 & 71.9 & 196.8 & 71.6 & 38 & -0.174 & 0.015 & Passive (no intervention) \\
4 & Karimi et al. (2009) & 107.8 & 9.07 & 106.3 & 11.62 & 16 & -0.144 & 0.036 & Passive (no intervention) \\
5 & Segumpan et al. (2018) & 3.28 & 0.65 & 3.37 & 0.65 & 45 & 0.14 & 0.013 & Traditional Learning \\
6 & Gan (2016) & 63.17 & 18.76 & 78.17 & 22.38 & 35 & 0.73 & 0.023 & Traditional learning \\
7 & Samuel et al. (2021) & 2.68 & 0.74 & 2.42 & 0.6 & 20 & -0.386 & 0.032 & Traditional learning \\
8 & Asanjarani et al. 2021 & 40.3 & 4.61 & 36 & 6 & 20 & -0.804 & 0.044 & Traditional learning \\
9 & Amirnudin et al.(2020) & 40.86 & 3.23 & 38.93 & 3.15 & 15 & -0.61 & 0.049 & Traditional learning \\
10 & Gholami et al. (2020) & 35.76 & 8.55 & 37.42 & 9.35 & 42 & 0.185 & 0.014 & Traditional learning \\
11 & Naseem et. al (2021) & 65.11 & 9.93 & 65.94 & 9.64 & 33 & 0.085 & 0.017 & Traditional learning \\
12 & Coruk et al. (2017) & 21.32 & 11.48 & 22.84 & 11.48 & 31 & 0.132 & 0.018 & Traditional learning \\
13 & Batton (2010) & 38.28 & 9.09 & 37.53 & 10.74 & 32 & -0.075 & 0.018 & Traditional learning \\
14 & Hocker (2017) & 3.99 & 1.23 & 3.9 & 1.25 & 63 & -0.073 & 0.009 & Passive (no intervention) \\
15 & Passolunghi et al. (2020) & 19,97 & 5,99 & 19,19 & 6,29 & 72,00 & -0.127 & 0,008 & Passive (no intervention) \\
\hline
\end{tabular}

$\operatorname{RE}$ Model $\left(\mathrm{Q}=62.3, \mathrm{df}=14, \mathrm{p}=0.00, \mathrm{I}^{2}=86.0 \%\right) \quad-0.076 \quad[-0.24,0.09]$

\begin{tabular}{|c|l|c|c|c|c|}
\hline & Scenario & $d_{p p c 2}$ & ci.lb & ci.ub & $\mathrm{I}^{2}$ \\
\hline 1 & All separated except Santos (2021) & -0.32 & -0.64 & 0.01 & $91.4 \%$ \\
2 & All separated & -0.31 & -0.62 & 0.00 & $90.5 \%$ \\
3 & All merged & -0.36 & -0.74 & 0.02 & $93 \%$ \\
4 & Only Jansen et al. (2013) merged & -0.34 & -0.70 & 0.01 & $92.8 \%$ \\
5 & Only Huang et al. (2014) merged & -0.33 & -0.67 & 0.01 & $92 \%$ \\
\hline
\end{tabular}

\section{Table S4}

Sensitivity analysis to the choice of keeping separated or merging distinct experimental groups described in the same study. The first line is the scenario selected for the main paper analysis

different enough game-based intervention. Moreover, since each experimental group did play a game, we did not consider discarding any group or to include it in the control group, as suggested in the Cochrane Handbook when more than one experimental study can be considered a form of control (as in the acupuncture vs. sham acupuncture vs. no intervention described in Higgins, Thomas, Chandler, Cumpston, Li, Page and Welch (2019)).

While the studies by Novak and Tassell (2015) and Walker (2018) did clearly describe distinct experiments with different games, in the two studies by Huang et al. (2014) and Jansen et al. (2013) the experimental groups could have been merged, since the same baseline game was used.

In order to test the impact of these alternative choices, we performed an additional sensitivity analysis for each possible merging scenario. The results are shown in table $\mathrm{S} 4$, showing how the overall value of $d_{p p c 2}$ changed insignificantly. The lowest $d_{p p c 2}$ was obtained with all the studies merged, but the confidence interval resulted higher and the value of $d_{p p c 2}$ not significant.

Regarding the statistical analysis of multiple experimental groups from the same study, the control group of each study was equally split among each of the experimental conditions, as per recommendation of the Cochrane Handbook for Systematic Reviews of Interventions (Higgins et al. (2019)). The large sensitivity analysis of the results (table 7 main paper) was used to account for the fact that this method only partially overcomes the unit-of-analysis error (because the resulting comparisons remain correlated).

\subsection{Data description}

The following table S5 describes, for each study, the final experimental data used in the meta-analysis and the source of each data. The numbers in bold represent the values imputed by the control group imputation described in section 2.1 . 


\section{Table S5a}

Data used in the meta-analysis and its sources.

\begin{tabular}{llrrrrr}
\hline & & \multicolumn{5}{c}{ Experimental group } \\
\cline { 3 - 7 } ID & Author(s) & Mean Pre & Std Pre & Mean Post & Std Post & N \\
\hline $\mathbf{1}$ & C-M. Hung, 2014 & 3.44 & 0.83 & 3.29 & 0.70 & 23.00 \\
\hline $\mathbf{2}$ & S-M WANG, 2020 & 20.43 & 8.69 & 18.90 & 8.73 & 73.00 \\
\hline $\mathbf{3}$ & H.M.Z. Alanaz, 2020 & 2.42 & 0.27 & 2.01 & 0.30 & 28.00 \\
\hline \multirow{2}{*}{$\mathbf{4}$} & \multirow{2}{*}{ B. Jensen et al, 2013 } & 38.20 & 12.00 & 34.80 & 10.30 & 48.00 \\
& & 42.50 & 14.00 & 37.10 & 10.10 & 52.00 \\
\hline \multirow{2}{*}{ A.J. Walker, 2018 } & 39.00 & 10.50 & 37.10 & 10.60 & 51.00 \\
\hline \multirow{2}{*}{$\mathbf{6}$} & \multirow{2}{*}{ Y.M. Huang, 2014 } & 29.36 & 8.08 & 23.04 & 4.67 & 25.00 \\
& & 31.26 & 12.14 & 27.04 & 9.95 & 24.00 \\
\hline $\mathbf{7}$ & \multirow{2}{*}{ E. Novak, 2015 } & 26.00 & 2.79 & 28.13 & 2.56 & 29.00 \\
& & 26.40 & 2.89 & 28.09 & 2.47 & 27.00 \\
\hline $\mathbf{8}$ & S. Vanbecelaere, 2020 & 2.87 & 1.25 & 2.92 & 1.32 & 16.00 \\
\hline $\mathbf{9}$ & E.N. Castellar, 2014 & 2.90 & 1.25 & 2.74 & 1.31 & 14.00 \\
\hline $\mathbf{1 0}$ & M. Rocha, 2020 & 35.00 & 5.00 & 33.00 & 5.00 & 25.00 \\
\hline & & 19.69 & 7.158 & 21.01 & 8.977 & 77 \\
\hline
\end{tabular}

\section{Table S5b}

\begin{tabular}{|c|c|c|c|c|c|c|c|}
\hline \multirow[b]{2}{*}{ ID } & \multirow[b]{2}{*}{ Author(s) } & \multicolumn{5}{|c|}{ Control group } & \multirow[b]{2}{*}{ Source } \\
\hline & & Mean Pre & Std Pre & Mean Post & Std Post & $\mathrm{N}$ & \\
\hline 1 & C-M. Hung, 2014 & 3.24 & 0.67 & 3.37 & 0.73 & 23 & tbl. 5,6 (pg. 160) \\
\hline 2 & S-M WANG, 2020 & 23.56 & 8.77 & 23.49 & 9.30 & 70 & tbl. 2, (pg. 193) \\
\hline \multirow[t]{2}{*}{3} & H.M.Z. Alanaz, 2020 & 2.44 & 0.27 & 2.78 & 0.21 & 32 & $\begin{array}{l}\text { tbl. } 1 \text { (pg. 95), } \\
\text { tbl. } 5 \text { (pg.102) }\end{array}$ \\
\hline & & 40.00 & 13.40 & 38.00 & 13.20 & 56 & \\
\hline \multirow[t]{2}{*}{4} & B. Jensen et al, 2013 & 40.00 & 13.40 & 38.00 & 13.20 & 56 & tbl. 2 (pg. 193) \\
\hline & & 40.00 & 13.40 & 38.00 & 13.20 & 56 & \\
\hline \multirow{2}{*}{5} & \multirow{2}{*}{ A.J. Walker, 2018} & 32.24 & 11.38 & 31.38 & NA & 25 & \\
\hline & & 32.24 & 11.38 & 31.38 & NA & 24 & tbl. 2.1 (pg. 85) \\
\hline \multirow{2}{*}{6} & \multirow{2}{*}{ Y.M. Huang, 2014} & 26.19 & 2.84 & 25.97 & NA & 29 & Table 8 (pg. 16) \\
\hline & & 26.19 & 2.84 & 25.97 & NA & 27 & Table 9 (pg. 17) \\
\hline \multirow{2}{*}{6} & \multirow{2}{*}{ E. Novak, 2015} & 3.01 & 0.94 & 2.94 & NA & 14 & tbl. 2 (pag. 128) \\
\hline & & 3.01 & 0.94 & 2.94 & NA & 16 & \\
\hline 8 & S. Vanbecelaer, 2020 & 28.01 & 4.30 & 28.79 & 3.82 & 101 & tbl. A1 (pg 13) \\
\hline 9 & E.N. Castellar, 2014 & 41.00 & 6.00 & 37.00 & 6.00 & 26 & fig. 4 (pg.25) \\
\hline 10 & M. Rocha, 2020 & 19.74 & 7.57 & 19.16 & NA & 77 & tbl. 4 (pg. 137) \\
\hline
\end{tabular}

\section{References}

Carey, E., Hill, F., Devine, A., Szúcs, D., 2017. The modified abbreviated math anxiety scale: A valid and reliable instrument for use with children Frontiers in psychology 8,11 .

Duval, S., Tweedie, R., 2000. Trim and fill: a simple funnel-plot-based method of testing and adjusting for publication bias in meta-analysis. Biometrics 56, 455-463.

Halpern, S.D., Berlin, J.A., Rothstein, H., Sutton, A., Borenstein, M., 2005. Beyond conventional publication bias: Other determinants of data suppression. Publication bias in meta-analysis: Prevention, assessment and adjustments , 303-317.

Higgins, J.P., Thomas, J., Chandler, J., Cumpston, M., Li, T., Page, M.J., Welch, V.A., 2019. Cochrane handbook for systematic reviews of interventions. John Wiley \& Sons.

Huang, Y.M., Huang, S.H., Wu, T.T., 2014. Embedding diagnostic mechanisms in a digital game for learning mathematics. Educational Technology Research and Development 62, 187-207.

Hung, C.M., Huang, I., Hwang, G.J., 2014. Effects of digital game-based learning on students' self-efficacy, motivation, anxiety, and achievements 
in learning mathematics. Journal of Computers in Education 1, 151-166.

Jamieson, J.P., Peters, B.J., Greenwood, E.J., Altose, A.J., 2016. Reappraising stress arousal improves performance and reduces evaluation anxiety in classroom exam situations. Social Psychological and Personality Science 7, 579-587.

Jansen, B.R., Louwerse, J., Straatemeier, M., Van der Ven, S.H., Klinkenberg, S., Van der Maas, H.L., 2013. The influence of experiencing success in math on math anxiety, perceived math competence, and math performance. Learning and Individual Differences 24, $190-197$.

Kaur, B., Wong, K.Y., Yee, L.P., 2009. Mathematics education: the Singapore journey. volume 2. World Scientific.

Lim, S.Y., Chapman, E., 2013. An investigation of the fennema-sherman mathematics anxiety subscale. Measurement and Evaluation in Counseling and Development 46, 26-37.

Mkhize, M.V., Maistry, S.M., 2017. Pre-service accounting teachers' attitudes to mathematics. South African Journal of Education 37, 1-12.

Morris, S.B., 2008. Estimating effect sizes from pretest-posttest-control group designs. Organizational research methods 11,364-386.

Novak, E., Tassell, J., 2015. Using video game play to improve education-majors' mathematical performance: An experimental study. Computers in Human Behavior 53, 124-130.

Passolunghi, M.C., De Vita, C., Pellizzoni, S., 2020. Math anxiety and math achievement: The effects of emotional and math strategy training. Developmental science 23, e12964.

Pierpaolo Dondio, M.R., 2021. Happy maths: an. Technical report .

Reavis, P.S., 1987. Mathematics anxiety and the relationship between attitude, sex, ethnicity and achievement in mathematics in three high school curriculum tracks. .

Santos, F.H., 2021. Calcularis efficacy in children with developmental dyscalculia: Testing a shorter protocol. .

Team, R.C., et al., 2018. R: a language and environment for statistical computing, version 3.5. 1. Vienna, Austria: R Foundation for Statistical Computing .

Thompson, R., Wylie, J., Hanna, D., 2016. Maths anxiety in psychology undergraduates: A mixed-methods approach to formulating and implementing interventions. Psychology Teaching Review 22, 58-68.

Viechtbauer, W., 2010. Conducting meta-analyses in $r$ with the metafor package. Journal of statistical software 36, 1-48.

Walker, A.J., 2018. Is Mathematics Anxiety Amenable to Intervention in School-Aged Children? The University of Manchester (United Kingdom).

Wright, E.K.C., 2017. Understanding Math anxiety in children: deciphering the contribution of math achievement, working memory, and general anxiety. Ph.D. thesis. University of South Carolina.

Wu, S., Amin, H., Barth, M., Malcarne, V., Menon, V., 2012. Math anxiety in second and third graders and its relation to mathematics achievement. Frontiers in psychology 3, 162.

Wu, S.S., Willcutt, E.G., Escovar, E., Menon, V., 2014. Mathematics achievement and anxiety and their relation to internalizing and externalizing behaviors. Journal of learning disabilities 47, 503-514.

Young, C.B., Wu, S.S., Menon, V., 2012. The neurodevelopmental basis of math anxiety. Psychological science 23, $492-501$. 